\title{
Properties of the Passive Film Formed on Interstitially Hardened AISI 316L Stainless Steel
}

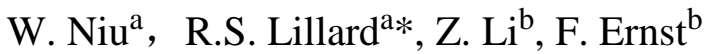 \\ a Department of Chemical and Biomolecular Engineering, \\ The University of Akron, \\ Akron, Ohio 44325, USA. \\ $\mathrm{b}$ Department of Materials Science and Engineering, \\ Case Western Reserve University, \\ 10900 Euclid Ave, Cleveland, Ohio 44106, USA.
}

\begin{abstract}
The passive-film on interstitially hardened AISI 316L stainless steel was studied in $0.1 \mathrm{M} \mathrm{NaCl}$ solution using electrochemical impedance spectrometry (EIS) and surface analytical techniques. The interstitially hardened AISI 316L was achieved via low-temperature paraequilibrium carburization. EIS experimental data were fitted and analyzed by an equivalent-circuit model that incorporated two time constants: one representing the properties of the carburized layer and one representing those of the passive film. To validate the model a series of samples with varying carburized layer thickness were prepared by successive polishing. In addition to EIS, these samples were analyzed by XPS (X-ray photoelectron spectrometry) to determine the chemical composition of the passive film and carburized layer. A consistent correlation was observed between the EIS response and the chemical compositions of the passive film and carburized layers. Supporting data from long term immersion tests are also reported.
\end{abstract}

Key words: Austenitic stainless steel, AISI 316L, interstitial hardening, surface engineering passivity, electrochemical impedance spectrometry, X-ray photoelectron spectrometry.

*Corresponding author: lillard@uakron.edu 


\section{Introduction}

Surface hardening (or, more general, surface engineering) of alloys has been a central theme of materials technology. For stainless steel and related alloys, interstitial hardening via a lowtemperature gas carburizing process has been developed by Heurer and Ernst[1-7]. The process is based on infusing carbon through the alloy surface at low temperature - a temperature low enough to kinetically suppress carbide precipitation but still high enough to enable carbon diffusion into technologically useful depths $(>25 \mu \mathrm{m})$ within acceptable processing times $(90 \mathrm{ks})[1$, 2]. Without changing the shape or dimensions of alloy parts, the process produces a graded carbon concentration-depth profile from the alloy surface into the part. In austenitic stainless steel AISI316, for which the process has been developed originally, peak fractions of up to 14 at $\%$ of carbon in solid solution are observed near the surface. This corresponds to $\approx 10^{5}$ times the roomtemperature equilibrium solubility limit of carbon. The dissolved carbon stabilizes the FCC (face-centered cubic) crystal structure of austenite and lowers the martensite start temperature. The carburized layer dramatically improves hardness $(\approx 5$ times $)$, wear resistance $(\approx 100$ times), and high-cycle fatigue life $(\approx 100$ times). For example, surface Vickers hardness values of $1200 \mathrm{HV} 25$ have been obtained for base material with a Vickers hardness of 250HV25 [3]. The substantial enhancement of high-cycle fatigue life has also been observed and is the result of a compressive biaxial stress of 2 to $3 \mathrm{GPa}$ that the high concentration of interstitial carbon generates near the alloy surface [3].

With respect to corrosion resistance, it has been reported that interstitial hardening (IH) with low-temperature paraequilibrium carburization significantly improves the resistance of AISI316L to pitting in chloride-containing solution [4-6]. Martin et al. evaluated the pitting corrosion resistance of IH AISI-316L and N08367 superaustenitic stainless steel in $0.6 \mathrm{M} \mathrm{NaCl}$. They demonstrated that, while the pitting potential for non-treated AISI-316L was on average $0.180 \mathrm{~V}$ vs. SCE, the low temperature carburized AISI-316L shows no sign of pitting or crevice corrosion up to potentials above $0.900 \mathrm{~V}$ vs. SCE $[4,5]$. Subsequently, Heuer et al. proposed that pitting corrosion of IH AISI-316L may be of chemo-mechanical origin [8]. The basis for that hypothesis was the experimental observation that the passive layer on IH AISI-316L was thinner than that on non-treated AISI-316L at equivalent applied potentials. This lead to the proposal that electrochemical breakdown results from local mechanical destruction of the passive layer when its thickness reaches a critical value - e.g. in the form of stress-induced thickness undulations in the passive film, which lead to increased local electric field strength and eventually breakdown in the undulation valleys [9]. 
In the work presented here, we focus on the mechanism of passive film growth on IH AISI316L. To accomplish this we investigate the composition of the near surface region of interstitially hardened AISI-316L and compare it with that on non-treated AISI-316L. We emphasize the development of a proper EIS equivalent-circuit (EC) model and correctly interpreting the physical meaning of the parameters. For this purpose, we evaluated the results of complementary studies by LOM (light-optical microscopy), SEM (scanning electron microscopy), and XPS (Xray photoelectron spectrometry) to quantitatively interpret the EC model we used to fit the EIS data.

\section{Experimental Procedures}

\subsection{Sample Preparation}

Samples used in the present work were $50 \mathrm{~mm} \times 50 \mathrm{~mm}$ coupons of AISI316L austenitic stainless steel $(18 \mathrm{wt} \% \mathrm{Cr}, 10 \mathrm{wt} \% \mathrm{Ni}, 3 \mathrm{wt} \% \mathrm{Mo}, 2 \mathrm{wt} \% \mathrm{Mn}, 0.03 \mathrm{wt} \% \mathrm{C}$ and $0.75 \mathrm{wt} \% \mathrm{Si})$ with a thickness of $0.38 \mathrm{~mm}$. Samples were tested in the as received condition and interstitially hardened (IH) by the low temperature paraequilibrium carburizing process. Carburization was carried out in a computer-controlled gas furnace. The process included a "surface activation step" of $14 \mathrm{ks}$ $(4 \mathrm{~h})$ in $\mathrm{HCl}$ gas at $600 \mathrm{~K}\left(325^{\circ} \mathrm{C}\right)$ to strip the passive film before the actual process of infusing carbon from a $\mathrm{CO}-\mathrm{CO}_{2}$ gas mixture for $80 \mathrm{ks}(22 \mathrm{~h})$ at $740 \mathrm{~K}\left(470{ }^{\circ} \mathrm{C}\right)$. This process resulted in a carburized layer with the thickness up to $25 \mu \mathrm{m}$. Figure 1 shows a typical optical micrograph of the cross section of the IH AISI316L specimen. The carburized layer is characterized by an interface with the AISI316L substrate since it is more resistant to the chemical etchant. The carburized layer thickness is $27 \mu \mathrm{m}$. Prior to electrochemical testing the non-treated AIS316L samples were polished with 600 grit $\mathrm{SiC}$ paper, degreased using ultrasonic by acetone, ethanol solution followed by deionized water. The IH samples were tested in their as-prepared condition and only cleaned by deionized water unless otherwise indicated in the text.

To examine the effect of surface carbon concentration on corrosion properties, corrosion samples with different surface carbon concentrations were prepared by successively polishing off thin layers - 5, 10, 20 and $35 \mu \mathrm{m}$ - from the surface of a IH AISI316L specimen. Grinding was carried out using $\mathrm{SiC}$ paper, and the thickness of the removed layer was measured by optical profilometry, using the depth change relative to a scratch made on the surface just outside the test area.

To investigate the galvanic interaction between the interstitially hardened surface layer and the AISI 316 substrate, samples were prepared with intentional surface defects: A scratch was 
created using a diamond pen, resulting in a defect with dimensions of $3 \mathrm{~mm} \times 20 \mu \mathrm{m}$ with a maximum depth of $11 \mu \mathrm{m}$ (measured via 3D optical profilometry).

\subsection{Electrochemical Tests}

Electrochemical tests were performed in $0.1 \mathrm{M} \mathrm{NaCl}$ at room temperature using a flat cell. An SCE (saturated calomel electrode) was used as the reference electrode and potentials measured in this paper all refer to the SCE scale. A platinum mesh was used as the counter electrode. The working electrode was clamped to the cell against a "crevice-free" gasket with an exposure area of $1.0 \mathrm{~cm}^{2}$ to the electrolyte.

Anodic and cathodic potentiodynamic polarization curves from IH AISI316L samples were recorded in separate experiments. The scan rate was set to $0.6 \mathrm{~V} / \mathrm{h}$. The polarizations started at the OCP (open circuit potential) and run in only one direction, either anodic or cathodic. Before the potentiodynamic test, a long-term OCP was monitored for 4 days to insure steady state. EIS measurements were conducted at the OCP using a $10 \mathrm{mV}$ amplitude AC (alternating current) signal. The frequency range was between $100 \mathrm{kHz}$ and $1 \mathrm{mHz}$ at 10 points per decade.

\subsection{Surface Characterization}

The surface morphology of IH 316L was characterized by SEM and light-optical microscopy. The surface composition was analyzed by XPS (X-ray photoelectron spectrometry), utilizing monochromatic $\mathrm{Al} \mathrm{K} \alpha$ radiation with a $100 \mu \mathrm{m}$ spot size. Composition-depth profiles were obtained by sputtering with $2 \mathrm{keV}$ Ar ions and intermittent XPS analysis of the freshly exposed surface using a collection angle of $40^{\circ}$.

\section{Results and Discussion}

\subsection{Potentiodynamic Polarization Curves}

Figures $2 \mathrm{a}$ and $2 \mathrm{~b}$ present typical anodic and cathodic potentiodynamic polarization curves for non-treated and IH AISI316L, respectively. In Figure 2a, it can be seen that the anodic part of the non-treated sample is characterized by a passive region with a passive current density $i_{\mathrm{p}}=(0.5 \pm 0.3) \mu \mathrm{A} / \mathrm{cm}^{2}$. With increased applied potential, metastable-pitting activity becomes 
dominant until the pitting potential is reached and the transition to stable pitting ensues at $0.6 \mathrm{~V}$ vs. SCE. Light-optical microscopy after test revealed dispersed pits on the surface. The cathodic portion of the curve was controlled by oxygen reduction with the current density limited by oxygen diffusivity. In Figure $2 \mathrm{~b}$, data from the $\mathrm{IH}$ sample, the anodic portion of the curve exhibits a passive region with similar $i_{\mathrm{p}}=0.9 \mu \mathrm{A} / \mathrm{cm}^{2}$ as the non-treated AISI316L up to $0.5 \mathrm{~V}$ vs SCE. In contrast to the non-treated sample, there is little to no metastable pitting behavior in the passive region of the curve. In this case, light-optical microscopy after polarization revealed no surface pits. While, a "break-away potential" was observed for this sample at much higher potentials than the measured $E_{\text {pit }}$ for non-treated AISI316L the lack of pitting on the sample after the test and a negative hysteresis in the reverse curve indicated that this potential was related to transpassivity, caused by either Fe (II) oxidation or solution oxidation. The cathodic curve of the IH sample is similar to that the non-treated 316L, controlled by oxygen diffusivity.

Table 1 summarizes critical electrochemical parameters from the potentiodynamic polarization tests. The polarization resistance, $R_{\mathrm{p}}$, was calculated from the Tafel slopes using the SternGeary approximation [10]. As seen in the table, the anodic and cathodic Tafel slope are almost the same for treated and non-treated AISI316L. Also shown in Table 1, low temperature carburization shifts the corrosion potential of AISI316L $60 \mathrm{mV}$ in the positive direction. The corrosion current density $i_{\text {corr }}$ of the $\mathrm{IH}$ sample is somewhat lower and the polarization resistance is higher, though but they are of the same magnitude as similar to those measured for non-treated AISI316L. Thus, interstitial hardening by low temperature carburization does not result in a significant change in corrosion rate [11].

\subsection{EIS Response and Proposed Equivalent-Circuit Model}

Figure 3 presents typical EIS data from IH and non-treated AISI316L exposed to $0.1 \mathrm{M} \mathrm{NaCl}$ solution in the form of Nyquist and Bode plots. Nyquist plots for both IH and non-treated samples show only a single RC (resistance-capacitance) time constant. However, the Bode phase plots for the IH AISI316L show two time constants, while the non-treated samples only show one. This finding for the non-treated sample is consistent with the EIS data found in the literature for the passive dissolution of AISI316L, where the EC shown in Figure 4a has been used to represent the EIS response [12]. In this model, $R_{\mathrm{Sol}}$ is the solution resistance, $R_{\mathrm{CT}}$ is a resistance associated with charge transfer, $C P E_{\mathrm{OX}}$ is a constant phase element associated with the capacitance of the passive oxide film, and $W_{\mathrm{OX}}$ is a Warburg impedance associated with transport of point defects in the passive film. The constant phase element is used in place of a capacitor to compensate the non-homogeneity of the system. The Warburg-type impedance represents the low-frequency re- 


\subsection{EIS Model Validation}

A sequence of EIS and XPS experiments was conducted to validate the hypothesis that the second time constant observed in the data from IH AISI316L was associated with the intrinsic resistivity and capacitance of the carburized layer. In those experiments, a thin (either 5, 10, 20, or $35 \mu \mathrm{m}$ thick) layer was removed from the IH sample by grinding, resulting in a series of samples with different carburized-layer thicknesses and different surface concentrations of carbon. For each of these samples, as well as for an IH sample without surface layer removal, EIS data were acquired after $0.35 \mathrm{Ms}$ (96 hours) of immersion in $0.1 \mathrm{M} \mathrm{NaCl}$ solution at the OCP. After the EIS experiment the sample was removed and the chemical composition of the near surface was determined using XPS. Figure 5 and Table 2 present the results of the EIS experimental data as a function of layer thickness. Consistent with the model, decreasing the thickness of the carburized layer decreases the resistance $R_{\mathrm{CL}}$. Correspondingly, $C P E_{\mathrm{Ox}}$ decreases with decreasing layer thickness. To further validate the model, we have calculated the corresponding carburized layer resistivity from the relationship:

$$
\rho=\frac{R_{\mathrm{CL}} \cdot A}{L}
$$

where $L$ is the layer thickness and $A$ is the electrode surface layer exposed to solution $\left(1 \mathrm{~cm}^{2}\right.$ in this study). Assuming the carburized layer is $27 \mu \mathrm{m}$ thick (Figure 1), we calculate the remaining carburized layer thicknesses after $0,5,10$, and $20 \mu \mathrm{m}$ surface layer removal to be $27,22,17$, and 

$\mathrm{M} \Omega \mathrm{m}$. As would be anticipated from our model, the intrinsic resistivity for each layer is approximately the same and the small decrease with layer thickness is likely due to the decreasing average carbon concentration in the carburized layer with increasing depth below the surface, as observed in carbon concentration-depth profiles obtained by XRD (X-ray diffractometry) [3, 16].

It is also possible to calculate the average oxide thickness from the constant phase element of the $C P E_{\mathrm{ox}}$ parameters. First, the oxide capacitance is calculated in accordance with references [17-19] using the relationship:

$$
C_{\mathrm{ox}}=Q\left(\omega_{\mathrm{m}}^{\prime \prime}\right)^{\alpha-1}
$$

where $Q$ is fitted from the $C P E_{\mathrm{ox}}, \omega_{\mathrm{m}}^{\prime \prime}$ is the frequency at which the imaginary part of the impedance has its maximum, and $\alpha$ is the exponent of $C P E_{\mathrm{Ox}}$. From $C_{\mathrm{OX}}$, the thickness of the oxide is calculated assuming:

$$
C_{\mathrm{ox}}=\frac{\varepsilon \cdot \gamma}{\kappa \cdot L}
$$

where $\varepsilon$ is the dielectric constant of the oxide film (15.6 is used for austenite stainless steel [12, 20-22]), $\gamma$ is the surface roughness factor (1.2 for an iron ground to 600 grit $\mathrm{SiC}$ ), $L$ is the film thickness, and $\kappa=1.13 \mathrm{~cm}^{2} \mu \mathrm{F}^{-1} \mathrm{~nm}^{-1}$. The calculation assumes that the capacitance obtained primarily owes to the passive film and the contribution from electrical double layer capacitance can be neglected. The calculated oxide passive film thicknesses are around $0.6 \mathrm{~nm}$, which is reasonable for passive films formed on stainless steel in low chloride containing solution as compared literature values of oxide thicknesses which between $0.5 \mathrm{~nm}$ and $6 \mathrm{~nm}$ [8, 23-26].

With respect to the values of the other parameters in Table $2, R_{\mathrm{CT}}$ increases with decreasing layer thickness and approaches that of AISI316L with $35 \mu \mathrm{m}$ removed from surface $\left(5.98 \times 10^{6}\right.$ $\Omega \mathrm{cm}^{2}$ ). As it relates to the Warburg element in our circuit, the magnitude of its impedance $Z_{\mathrm{W}}$ is given by

$$
Z_{\mathrm{W}}=\sigma(\omega)^{-1 / 2}(1-j)
$$

where $\sigma$ is the Warburg coefficient. $Z_{\mathrm{W}}$ can also be described in terms of real and imaginary components $Z_{\mathrm{W}^{\prime}}$ and $Z_{\mathrm{W}}{ }^{\prime \prime}$, and in the limiting case when $\omega$ approaches zero, $Z_{\mathrm{W}^{\prime}}=\sigma K$, where $K$ is the diffusion factor. Experimentally, values of both $\sigma$ and $K$ are obtained through CNLS fitting of the data and the results are presented in Table 2. As seen in Table 2, $\sigma$ is two orders of magnitude larger for the IH sample with no surface removal and decreases with decreasing surface layer thickness. For the thinnest layer ( $35 \mu \mathrm{m}$ removed), the Warburg coefficient approaches the same magnitude as the non-treated AISI316L. The Warburg coefficient $\sigma$ is of interest as it has been 


\subsection{Mechanism of Passivation}

The samples that provided the EIS data in Table 3 were also studied using XPS. Figure 6 shows typical XPS concentration-depth profiles of IH and non-treated AISI316L samples. Each sample produced an oxygen signal characteristic of a thin passive film. That is, a maximum $\mathrm{O}$ signal is observed after relatively short sputter time (e.g. close to the sample surface). The other dominant element in the near-surface oxide is $\mathrm{Cr}$, observed with maximum concentration after about $30 \mathrm{~s}$ of Ar sputtering. After approximately $60 \mathrm{~s}$, the concentration of both $\mathrm{Cr}$ and oxygen were down and did not significantly change with further sputtering. The Fe concentration leveled at 70 at $\%$ after $180 \mathrm{~s}$ of sputtering.

To evaluate what material properties may be influencing the EIS data, we have tabulated the near surface concentrations of $\mathrm{Cr}$ and $\mathrm{C}$ as a function of layer removal in Table 3 . To illustrate 

$5 \mu \mathrm{m}$ thick layer was removed from the surface (Figure 6 a). From these data, the oxidized species $\mathrm{Cr}$ (III) and $\mathrm{Fe}$ (II) are re-plotted in Figure $7 \mathrm{a}$ after deconvoluting the Cr- and $\mathrm{Fe} 2 \mathrm{p}_{3 / 2}$ doublets. Although only three species are shown in this plot, the concentrations were calculated with respect to the total. Assuming that the passive film on IH samples is chromium rich oxide [8], one would anticipate a surface enrichment in $\mathrm{Cr}$ (III). Thus, the $\mathrm{Cr}$ (III) peak in Figure $7 \mathrm{a}$ at $0.24 \mathrm{~s}$ (0.4 min, dashed line) represents the distance from the near-surface region in which the effects of surface contamination and bulk species are minimized. In Table 3 we have used the $\mathrm{Cr}$ peak from the XPS sputter profiles (Fig. 6) to represent the concentration in the near surface region. Correspondingly, we have tabulated the $\mathrm{C}$ concentration from the profiles at the same position. Finally in Figure 7b, it can be seen that the carbon-to-iron ratio in this near surface region is also larger than in the alloy core.

With respect to $\mathrm{Cr}$ concentration as a function of carburized layer thickness, Cr concentration increases inversely with layer thickness, that is without surface layer removal, the specimen had a near-surface $\mathrm{Cr}$ concentration of 19.5 at\%, while the IH AISI316L with $35 \mu \mathrm{m}$ removed from the surface had a maximum $\mathrm{Cr}$ concentration of 24.2 at $\%$ - similar to the value of $24.3 \mathrm{at} \%$ observed for non-treated AISI316L. The variation of the $\mathrm{Cr}$ concentration over the entire carburized layer thickness is shown in Table 3. In addition to the lower $\mathrm{Cr}$ concentration in the nearsurface region, the carbon concentration near the surface was highest in the as-prepared IH sample, 12 at $\%$ and decreased with increasing surface layer removal to approximately 5 at $\% \mathrm{C}$ at $20 \mu \mathrm{m}$ as shown in Table 3. Correspondingly the $[\mathrm{Cr}]$ and $\left[\mathrm{V}_{\mathrm{O}}\right]$ appear to be inversely related to the carbon concentration in the near surface region. According to the point-defect model [27], oxygen vacancies $\mathrm{V}_{\mathrm{O}}$ are formed at the metal-passive-film interface when a metal atom $m$ is transferred from its lattice site to a metal cation site on the metal sublattice of the barrier layer oxide $\left(M_{\mathrm{M}}\right)$ according to

$$
m \leftrightarrow M_{\mathrm{M}}+\frac{x}{2} \mathrm{~V}_{\mathrm{O}}+x \mathrm{e}^{-} .
$$

The oxygen vacancy then migrates to the film-solution interface, where it reacts with water to form an oxygen anion on the oxygen sublattice of the barrier layer. Recognizing that the minimal unit of the barrier layer is $M_{\mathrm{M}}\left(\mathrm{V}_{\mathrm{O}}\right)_{\mathrm{x} / 2}$ the formation of oxygen vacancies at the metal/film interface are a critical part of new film formation [32]. Therefore, a lower $\left[\mathrm{V}_{\mathrm{O}}\right]$ necessarily means that new film formation in IH samples is hindered with respect to AISI 316L. We propose that the concentration of $\mathrm{C}$ in the near-surface region hinders film formation due to strong $\mathrm{Cr}-\mathrm{C}$ bonding. That is, Cr transfer from its lattice site to a $C r_{\mathrm{M}}$ site on the metal sublattice of the barrier $\mathrm{Cr}$ 


\subsection{Long-Term Immersion Behavior of IH AISI 316}

The equivalent-circuit model described above was used to characterize the long-term EIS data of IH AISI316L. In these experiments, IH and non-treated AISI316L samples were exposed to $0.1 \mathrm{M} \mathrm{NaCl}$ aqueous solution for periods of up to 5.2 Ms (60 days). Typical EIS data as a function of immersion time are presented in Figure 8 in the form of Nyquist and Bode plots. While data were collected more frequently than shown, a limited number of curves are present so that trends observed over the $5.2 \mathrm{Ms}$ can be clearly seen. For the non-treated sample, the lowfrequency impedance decreased significantly with time over 1.3 Ms (15 days) of immersion. In comparison, the low-frequency impedance of the IH sample increased with time throughout the entire 5.2 Ms immersion period. Similar trends are observed in the Bode magnitude plots. The EIS data were fitted using the equivalent-circuit described in Figure 4 to characterize the changes in the IH sample. From those fits, it was determined that the resistance $R_{\mathrm{CL}}$ associated with the carburized layer was constant over $4.8 \mathrm{Ms}$ (55 days) at approximately $3 \times 10^{4} \Omega \mathrm{cm}^{2}$. However, the Warburg impedance associated with the oxide film decreased only a small amount (associated with an increase in transport). Figure 9 compares the changes in the charge transfer resistance $\left(R_{\mathrm{CT}}\right)$ and Warburg coefficient $\left(\sigma_{\mathrm{OX}}\right)$ with time. Collectively, these results indicate that the passive film formed on the IH AISI316L surface improves with time. 


\subsection{Galvanic Interaction at Defects}

Figure 10 presents EIS data collected from an IH AISI316L sample with an intentional defect as a function of immersion time. In the Nyquist plot, the real impedance of the sample (Z') increased with immersion time, suggesting that the corrosion rate was decreasing with time. In the Bode plots, the logarithmic magnitude of the impedance varies linearly with the logarithm of the frequency in the region from $1 \mathrm{~Hz}$ down to $1 \mathrm{mHz}$. Similarly, the phase angles are nearly constant with immersion time with a value around $80^{\circ}$ in the low-frequency region. This indicates that the response was dominated by the capacitance in the system [37] and the defect was still passive up to $1.1 \mathrm{Ms}$ (13 days) immersion in the test solution.

Figure 11 shows an SEM image of the intentional defect after the $1.1 \mathrm{Ms}$ immersion period. As seen in this figure there was no spalling or corrosion product associated with the scratch. Similarly, the surface area around the scratch also shows no signs of attack, indicating no galvanic action between the defect and the carburized material. This lack of galvanic action is explained by the long-term open-circle potential measurements shown in Figure 12. As can be seen, the IH AISI316L sample has a steady-state potential of approximately $130 \mathrm{mV}$ vs. SCE after $0.17 \mathrm{Ms}$ (48 hours). In comparison, while the open-circle potential of the non-treated AISI316L was $130 \mathrm{mV}$ vs. SCE at the onset of the immersion period, (nearly $200 \mathrm{mV}$ lower than that of the $\mathrm{IH}$ sample), it increased with time to approximately $80 \mathrm{mV}$ vs. SCE after $0.35 \mathrm{Ms}$ or 4 days) and remained steady thereafter. Thus, the OCP difference between the scratch and the carburized material was only $50 \mathrm{mV}$ during most of the $1.1 \mathrm{Ms}$ immersion period. These results indicate that minor damage that may occur during fabrication or in service will not result in premature failure of IH AISI316L components.

\section{Conclusions}

1. Interstitially hardened (IH) AISI316L by low temperature carburization possesses remarkably increased pitting resistivity (immunity) in $0.1 \mathrm{M} \mathrm{NaCl}$ aqueous solution. In fact, no pitting potential at all could be recorded in potentiodynamic polarization experiments and no localized corrosion was observed in long-term immersion tests.

2. The mechanism of passivation in IH samples was studied using electrochemical impedance spectrometry. An EIS model was developed that incorporated elements for the carburized layer and the passive film on its surface. The model provides a way to calculate the resistivity of the carburized layer, oxygen vacancy concentration, and diffusion coefficient in the passive film. 


\section{Acknowledgements}

This project was funded by the NEUP (Nuclear Engineering University Program) of DOE (U.S. Department of Energy) under contract NEUP-12-3451.

\section{References}

[1] Y. Cao, F. Ernst, G.M. Michal, Acta Materialia, 51 (2003) 4171-4181.

[2] F. Ernst, Y. Cao, G.M. Michal, A.H. Heuer, Acta Materialia, 55 (2007) 1895-1906.

[3] G.M. Michal, F. Ernst, H. Kahn, Y. Cao, F. Oba, N. Agarwal, A.H. Heuer, Acta Materialia, 54 (2006) 1597-1606.

[4] F.J. Martin, E.J. Lemieux, T.M. Newbauer, R.A. Bayles, P.M. Natishan, H. Kahn, G.M. Michal, F. Ernst, A.H. Heuer, Electrochemical and Solid-State Letters, 10 (2007) C76-C78.

[5] F.J. Martin, P.M. Natishan, E.J. Lemieux, T.M. Newbauer, R.J. Rayne, R.A. Bayles, H. Kahn, G.M. Michal, F. Ernst, A.H. Heuer, Metall and Mat Trans A, 40 (2009) 1805-1810.

[6] P.M. Natishan, R.A. Bayles, R. Rayne, T. Longazel, F.J. Martin, H. Kahn, A.H. Heuer, Corrosion, 68 (2012) 638-644.

[7] A.H. Heuer, F. Ernst, H. Kahn, A. Avishai, G.M. Michal, D.J. Pitchure, R.E. Ricker, Scripta Materialia, 56 (2007) 1067-1070.

[8] A.H. Heuer, H. Kahn, F. Ernst, G.M. Michal, D.B. Hovis, R.J. Rayne, F.J. Martin, P.M. Natishan, Acta Materialia, 60 (2012) 716-725.

[9] A.H. Heuer, H. Kahn, P.M. Natishan, F.J. Martin, L.E. Cross, Electrochim. Acta 58 (2011) 157-160. 
[10] R.G. Kelly, J.R. Scully, D.W. Shoesmith, R.G. Buchheit, Electrochemical techniques in corrosion science and engineering in: D.F. Bahrb (Ed.), CPC press, 2003.

[11] R.S. Lillard, D.P. Butt, T.N. Taylor, K.C. Walter, M. Nastasi, Corrosion Science, 39 (1997) 16051624.

[12] M.G.S. Ferreira, J.L. Dawson, Journal of The Electrochemical Society, 132 (1985).

[13] R.S. Lillard, G. Vasquez, Journal of The Electrochemical Society, 155 (2008) C162-C168.

[14] C.Y. Chao, L.F. Lin, D.D. Macdonald, Journal of The Electrochemical Society, 129 (1982) 18741879.

[15] D.D. Macdonald, R.Y. Liang, B.G. Pound, Journal of The Electrochemical Society, 134 (1987) 2981-2986.

[16] N. Agarwal, H. Kahn, A. Avishai, G. Michal, F. Ernst, A.H. Heuer, Acta Materialia, 55 (2007) 55725580.

[17] C.H. Hsu, F. Mansfeld, Corrosion, 57 (2001) 2.

[18] S.P. Harrington, T.M. Devine, Journal of The Electrochemical Society, 156 (2009) C154-C159.

[19] B. Hirschorn, M.E. Orazem, B. Tribollet, V. Vivier, I. Frateur, M. Musiani, Electrochimica Acta, 55 (2010) 6218-6227.

[20] M.E. Curley-Fiorino, G.M. Schmid, Corrosion Science, 20 (1980) 313-329.

[21] M. Pujar, N. Parvathavarthini, R.K. Dayal, J Mater Sci, 42 (2007) 4535-4544.

[22] G. Okamoto, T. Shibata, Corrosion Science, 10 (1970) 371-378.

[23] G. Okamoto, Corrosion Science, 13 (1973) 471-489.

[24] G.M. Bulman, A.C.C. Tseung, Corrosion Science, 13 (1973) 531-544.

[25] C.O.A. Olsson, D. Landolt, Electrochimica Acta, 48 (2003) 1093-1104.

[26] L. Wegrelius, F. Falkenberg, I. Olefjord, Journal of The Electrochemical Society, 146 (1999) 13971406.

[27] I. Nicic, D.D. Macdonald, Journal of Nuclear Materials, 379 (2008) 54-58.

[28] J. Sikora, E. Sikora, D.D. Macdonald, Electrochimica Acta, 45 (2000) 1875-1883.

[29] Y. Sun, Corrosion Science, 52 (2010) 2661-2670.

[30] J.L. Dawson, D.G. John, Journal of Electroanalytical Chemistry and Interfacial Electrochemistry, 110 (1980) 37-47.

[31] J. Bisquert, The Journal of Physical Chemistry B, 106 (2001) 325-333.

[32] D.D. Macdonald, A. Sun, Electrochimica Acta, 51 (2006) 1767-1779.

[33] G.E. Haslam, X.Y. Chin, G.T. Burstein, Phys Chem Chem Phys, 13 (2011) 12968-12974.

[34] G.H. Meier, W.C. Coons, R.A. Perkins, Oxid Met, 17 (1982) 235-262.

[35] R.N. Durham, B. Gleeson, D.J. Young, Oxid Met, 50 (1998) 139-165.

[36] H.J. Grabke, Corrosion, 51 (1995) 711-720.

[37] J.R. Scully, SILVERMAN, KENDIG, Electrochemical impedance: Analysis and Interpretation, in, ASTM, 1993. 


\section{List of Figure}

Fig. 1. Optical micrograph of a cross-sectioned IH AISI316L specimen after etching in $50 \mathrm{vol} \% \mathrm{HCl}+25 \mathrm{vol} \% \mathrm{HNO}_{3}+25 \mathrm{vol} \% \mathrm{H}_{2} \mathrm{O}$ for $60 \mathrm{~s}$.

Fig. 2. Anodic and cathodic potentiodynamic polarization curves generated for separate samples in $0.1 \mathrm{M} \mathrm{NaCl}$ at room temperature. (a) Non-treated AISI316L. (b) IH AISI 316L (740 K, 80ks).

Fig. 3. Experimental data and CNLS fitting of IH and non-treated AISI316L after 1.3Ms (15 days) of immersion in $0.1 \mathrm{M} \mathrm{NaCl}$ at room temperature. (a) Nyquist plot. (b) Bode phase plot. (c) Bode magnitude plot.

Fig. 4. Equivalent circuit model used to fit EIS data. (a) Non-treated 316L. (b) IH AISI 316L.

Fig. 5. Experimental data and CNLS fits of EC in Figure 4b for carburized AISI316L after removing surface layers with thicknesses 5, 10, 20, and $35 \mu \mathrm{m}$ (Figure 4a) for non-treated AISI316L in $0.1 \mathrm{M} \mathrm{NaCl}$ solution after 0.35 Ms (96 hours) of immersion. Symbols are the experimental data and lines are the fitting results. (a) Nyquist plot. (b) Bode phase plot. (c) Bode magnitude plot.

Fig. 6. Examples of XPS concentration-depth profiles. (a) IH AISI316L after removing a $5 \mu \mathrm{m}$ thick layer from the surface (b) Non-treated AISI316L. Not all experimental data are shown for clarity.

Fig. 7. Example of near-surface atom fractions in IH AISI316L after removing a $5 \mu \mathrm{m}$ thick layer from the surface. (a) Atom fractions of near-surface oxidized species and carbon. (b) Carbon-to-iron ratio.

Fig. 8. EIS experimental data (Nyquist plot, Bode phase and magnitude plot) as a function of immersion time in $0.1 \mathrm{M} \mathrm{NaCl}$ at room temperature. (a) Non-treated AISI 316L sample immersion in solution for 1.3 Ms (15 days). (b) IH AISI316L immersion in solution for 4.8 Ms (55 days).

Fig. 9. Charge transfer resistance $\left(R_{\mathrm{CT}}\right)$ and Warburg coefficient $\left(\sigma_{\mathrm{ox}}\right)$ changes on IH AISI316L with immersion time. 
Fig. 10. EIS experimental data for IH AISI 316L ( $743 \mathrm{~K}, 79 \mathrm{ks}$ ) with intentional defect (created scratch) as a function of immersion time. (a) Nyquist plot. (b) Bode phase plot. (c) Bode magnitude plot.

Fig. 11. SEM images of the intentional defect on IH AISI316L ( $743 \mathrm{~K}, 79 \mathrm{ks})$ after $1.1 \mathrm{Ms}(13$ days) immersion test. (a) Low magnification. (b) Higher magnification.

Fig. 12. Plot of open-circuit potential versus time from a comparative long-term immersion test of IH versus non-treated AISI316L. 
Table 1. Corrosion potential $\left(E_{\text {corr }}\right)$, corrosion current density $\left(i_{\text {corr }}\right)$, Tafel slope $\left(\boldsymbol{\beta}_{a}, \boldsymbol{\beta}_{c}\right)$, and polarization resistance $\left(R_{\mathrm{p}}\right)$ of non-treated and carburized AISI316L in $0.1 \mathrm{M} \mathrm{NaCl}$.

\begin{tabular}{cccccc}
\hline Sample & $\begin{array}{c}\boldsymbol{E}_{\text {corr }} \\
\text { V vs. SCE }\end{array}$ & $\begin{array}{c}\boldsymbol{i}_{\text {corr }} \\
\mathrm{A} / \mathrm{cm}^{2}\end{array}$ & $\begin{array}{c}\boldsymbol{\beta}_{\boldsymbol{a}} \\
\mathrm{mV} / \mathrm{dec}\end{array}$ & $\begin{array}{c}\boldsymbol{\beta}_{\boldsymbol{c}} \\
\mathrm{mV} / \mathrm{dec}\end{array}$ & $\begin{array}{c}\boldsymbol{R}_{\mathrm{p}} \\
\Omega_{\mathrm{cm}}{ }^{2}\end{array}$ \\
\hline Non-treated AISI 316L & 0.08 & $4.0 \times 10^{-8}$ & 460 & 180 & $1.40 \times 10^{6}$ \\
IH AISI 316L & 0.14 & $3.1 \times 10^{-8}$ & 490 & 180 & $1.40 \times 10^{6}$ \\
\hline
\end{tabular}

Table 2. Fitted values from the equivalent circuit parameters in Figure 4 obtained by CNLS for IH AISI 316L samples as a function of the amount of surface removed in $0.1 \mathrm{M} \mathrm{NaCl}$ after 96 hours of immersion. Data for a non-treated 316L are also shown.

\begin{tabular}{|c|c|c|c|c|c|c|c|c|}
\hline $\begin{array}{l}\text { Sample / } \\
\text { Removal } \\
\text { Thickness }\end{array}$ & $\Omega \mathrm{cm}^{2}$ & $\mathrm{Ss}^{\alpha} \mathrm{cm}^{-2}$ & $\alpha_{1}$ & $\Omega \mathrm{cm}^{2} \mathrm{~s}^{-1 / 2}$ & $K$ & $\Omega \mathrm{cm}^{2}$ & $\mathrm{~S} \mathrm{~s}^{\alpha} \mathrm{cm}^{-2}$ & $\alpha_{2}$ \\
\hline $0 \mu \mathrm{m}$ & $1.36 \times 10^{6}$ & $1.25 \times 10^{-4}$ & 0.98 & $1.30 \times 10^{6}$ & 3.6 & $4.32 \times 10^{4}$ & $2.72 \times 10^{-4}$ & 0.88 \\
\hline $5 \mu \mathrm{m}$ & $2.65 \times 10^{6}$ & $2.93 \times 10^{-5}$ & 0.95 & $5.57 \times 10^{6}$ & 10.0 & $3.45 \times 10^{4}$ & $2.23 \times 10^{-4}$ & 0.90 \\
\hline $10 \mu \mathrm{m}$ & $3.44 \times 10^{6}$ & $2.87 \times 10^{-5}$ & 0.95 & $4.16 \times 10^{6}$ & 7.0 & $2.08 \times 10^{4}$ & $3.24 \times 10^{-4}$ & 0.90 \\
\hline $20 \mu \mathrm{m}$ & $4.97 \times 10^{6}$ & $2.80 \times 10^{-5}$ & 0.95 & $1.38 \times 10^{6}$ & 4.0 & $6.45 \times 10^{3}$ & $5.57 \times 10^{-4}$ & 1.0 \\
\hline $35 \mu \mathrm{m}$ & $5.98 \times 10^{6}$ & $2.71 \times 10^{-5}$ & 0.94 & $1.94 \times 10^{4}$ & 1.0 & - & - & - \\
\hline AISI316L & $5.21 \times 10^{6}$ & $2.79 \times 10^{-5}$ & 0.94 & $1.49 \times 10^{4}$ & 1.0 & - & - & - \\
\hline
\end{tabular}


Table 3. Calculated values of the diffusion coefficient and oxygen vacancy concentration for nontreated and polished IH AISI 316L with corresponding near surface concentrations of $\mathrm{Cr}$ and $\mathrm{C}$ as measured by XPS.

\begin{tabular}{ccccc}
\hline $\begin{array}{c}\text { Sample / Removal } \\
\text { Thickness }\end{array}$ & $D$ & {$\left[\mathrm{~V}_{\mathrm{O}}\right]$} & {$[\mathrm{Cr}]$} & {$[\mathrm{C}]$} \\
\hline $0 \mu \mathrm{m}$ & $5.86 \times 10^{-17}$ & $4.55 \times 10^{19}$ & 19.5 & 12.5 \\
$5 \mu \mathrm{m}$ & $3.65 \times 10^{-16}$ & $4.26 \times 10^{18}$ & 20.0 & 10.7 \\
$10 \mu \mathrm{m}$ & $5.72 \times 10^{-16}$ & $4.56 \times 10^{18}$ & 21.3 & 9.5 \\
$20 \mu \mathrm{m}$ & $1.05 \times 10^{-15}$ & $1.01 \times 10^{19}$ & 22.5 & 5.8 \\
$35 \mu \mathrm{m}$ & $4.60 \times 10^{-15}$ & $3.39 \times 10^{20}$ & 24.2 & 2.2 \\
AISI 316L & $4.42 \times 10^{-15}$ & $4.57 \times 10^{20}$ & 24.3 & 2.4 \\
\hline
\end{tabular}


(a)

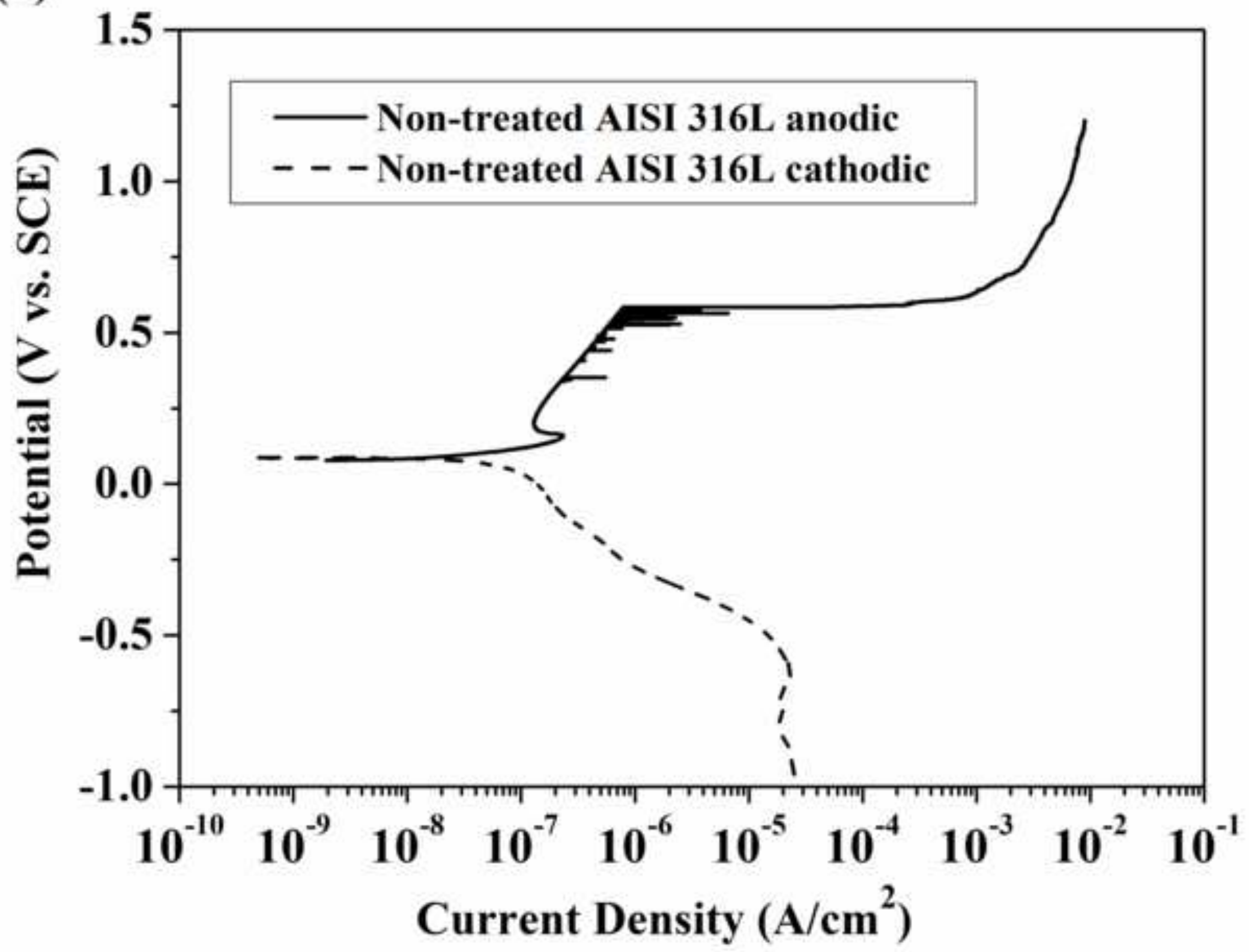


(b)

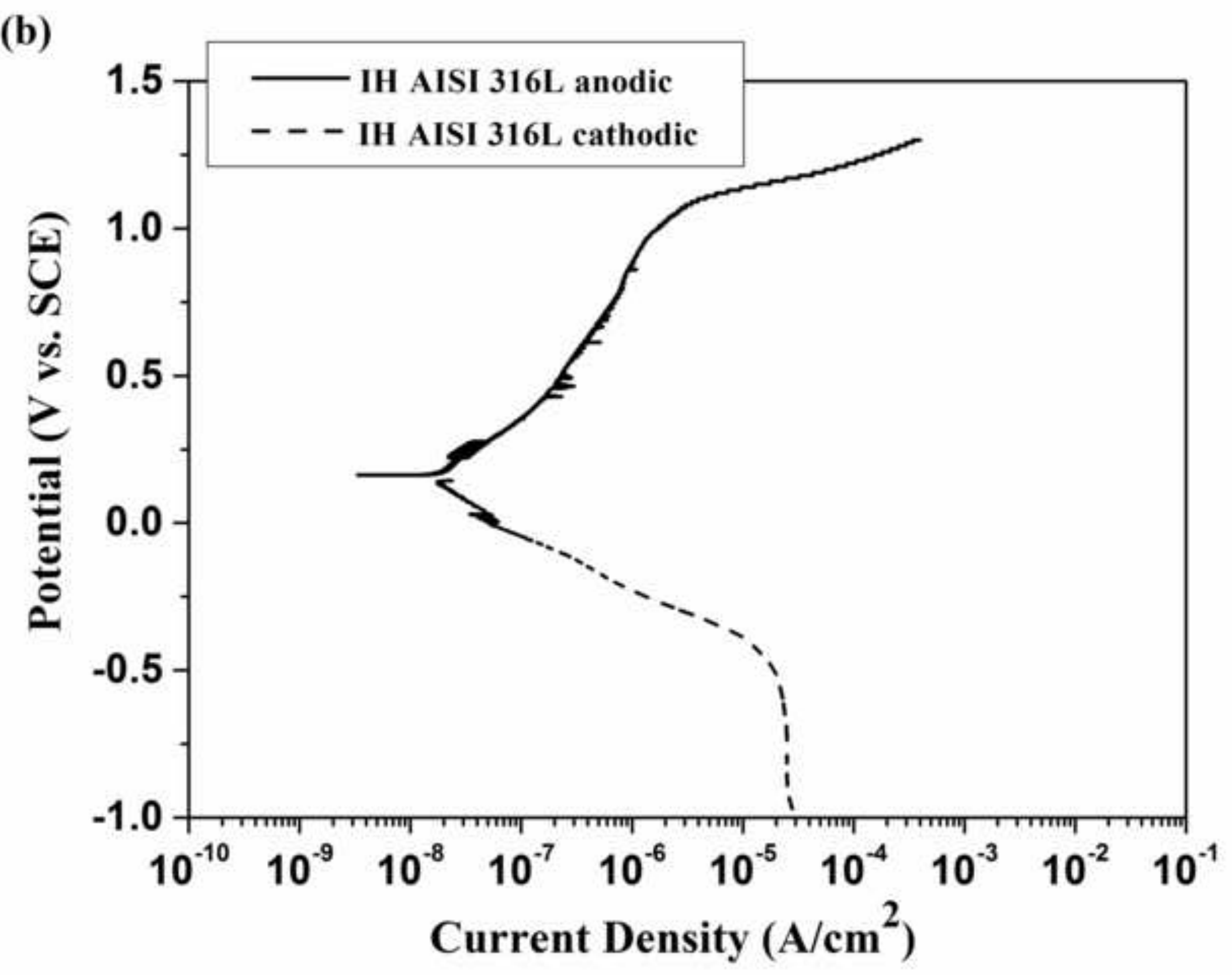


(a)

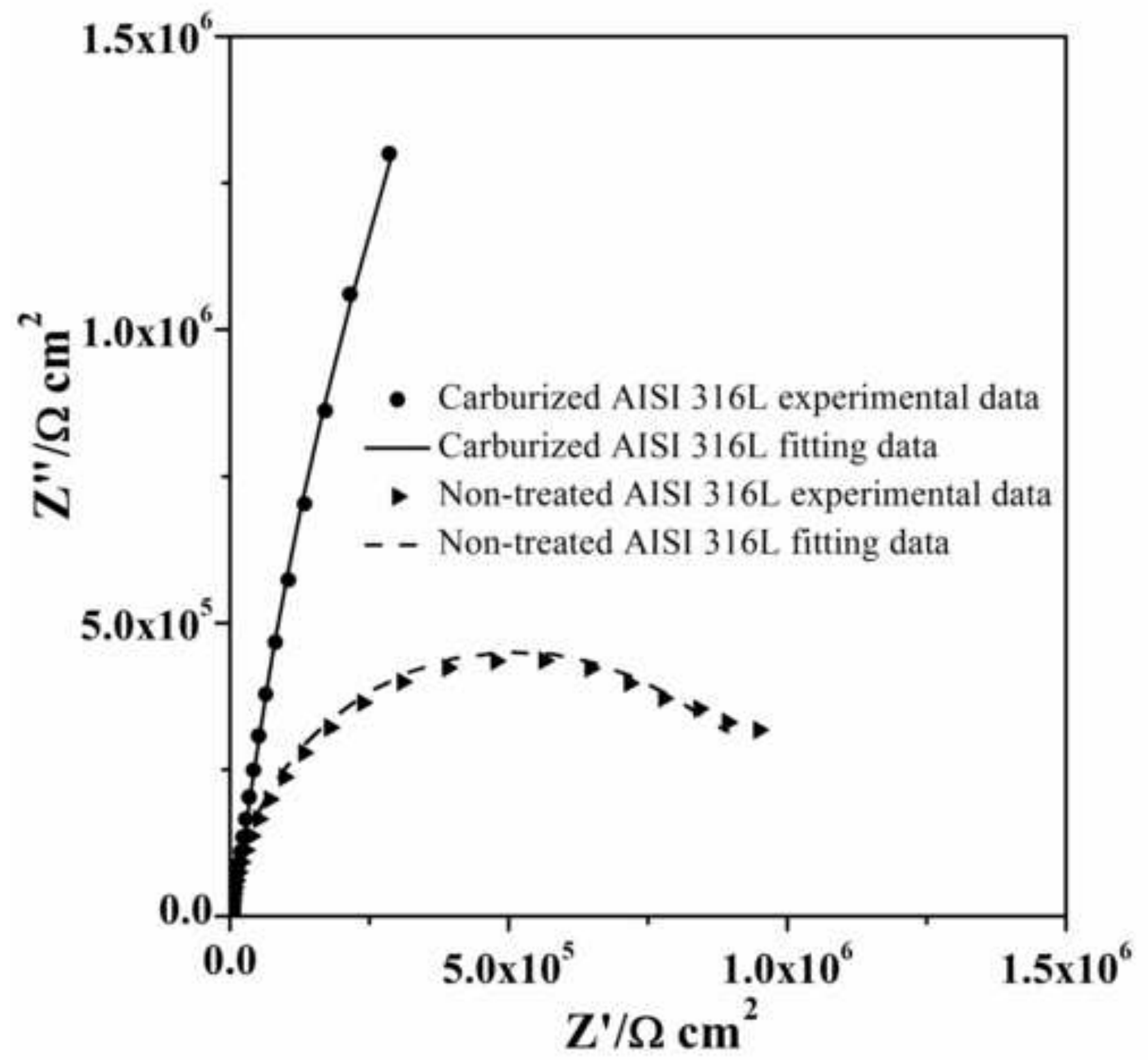


(b)

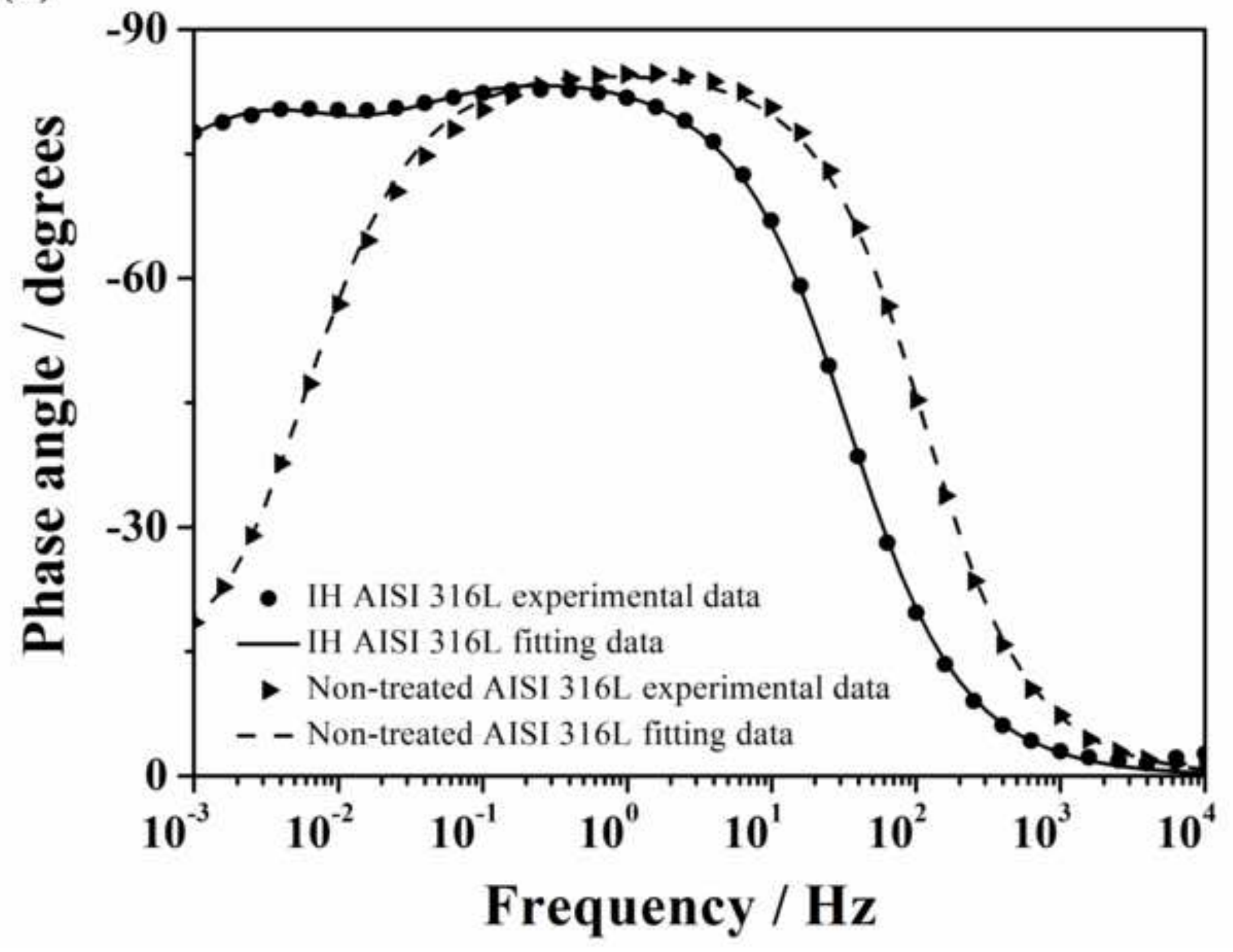


(c)

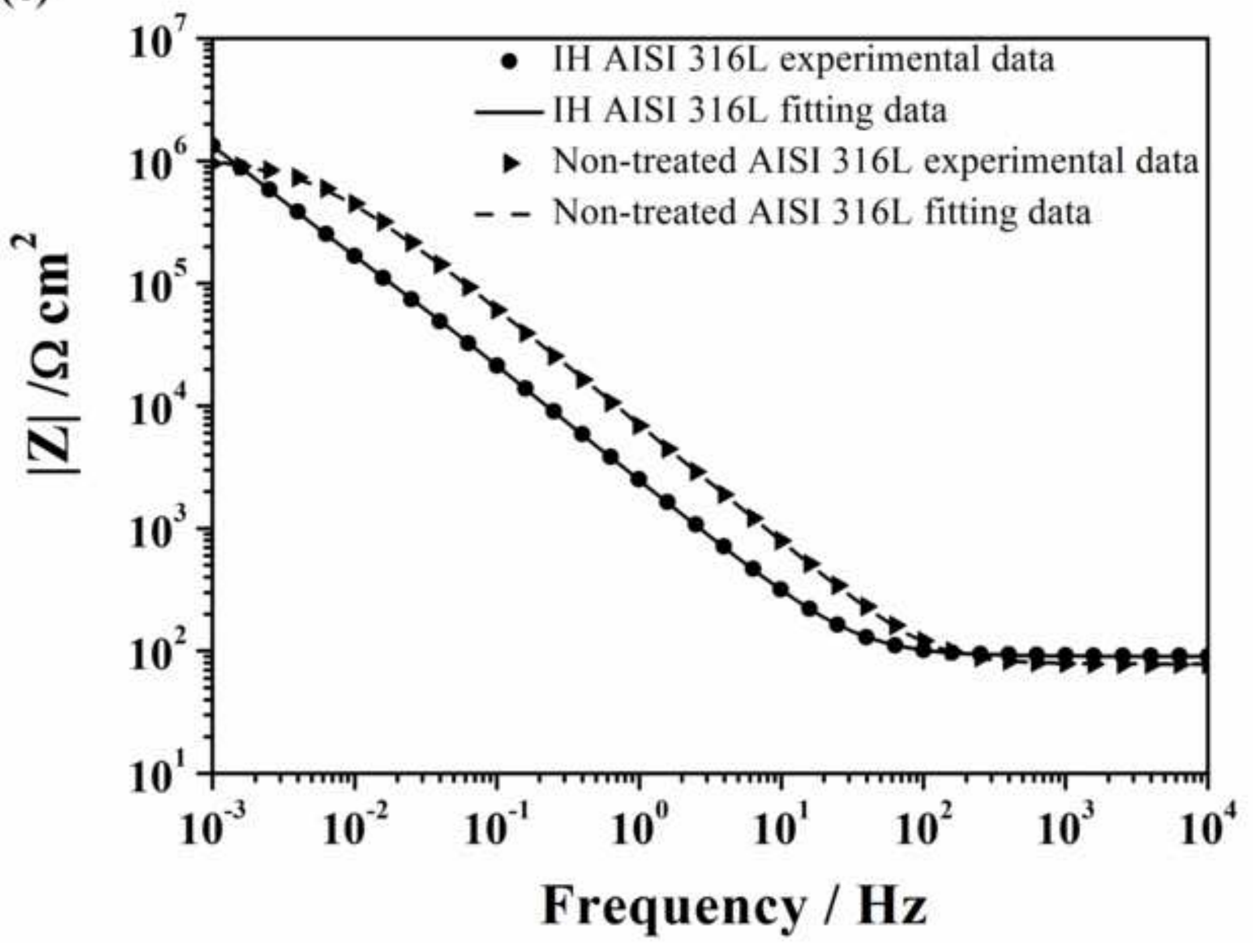


(a)

$\mathrm{CPE}_{\mathrm{OX}}$

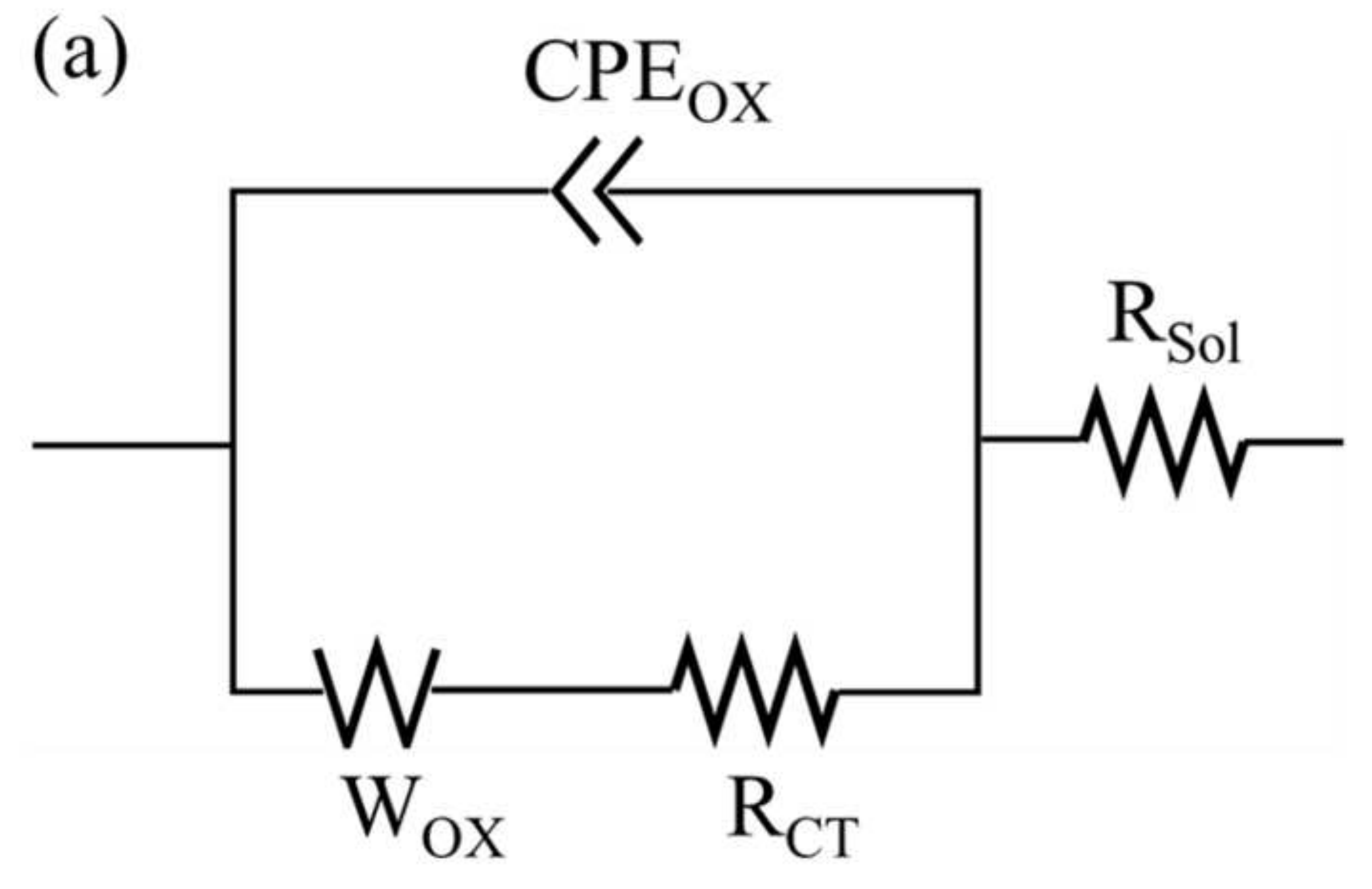



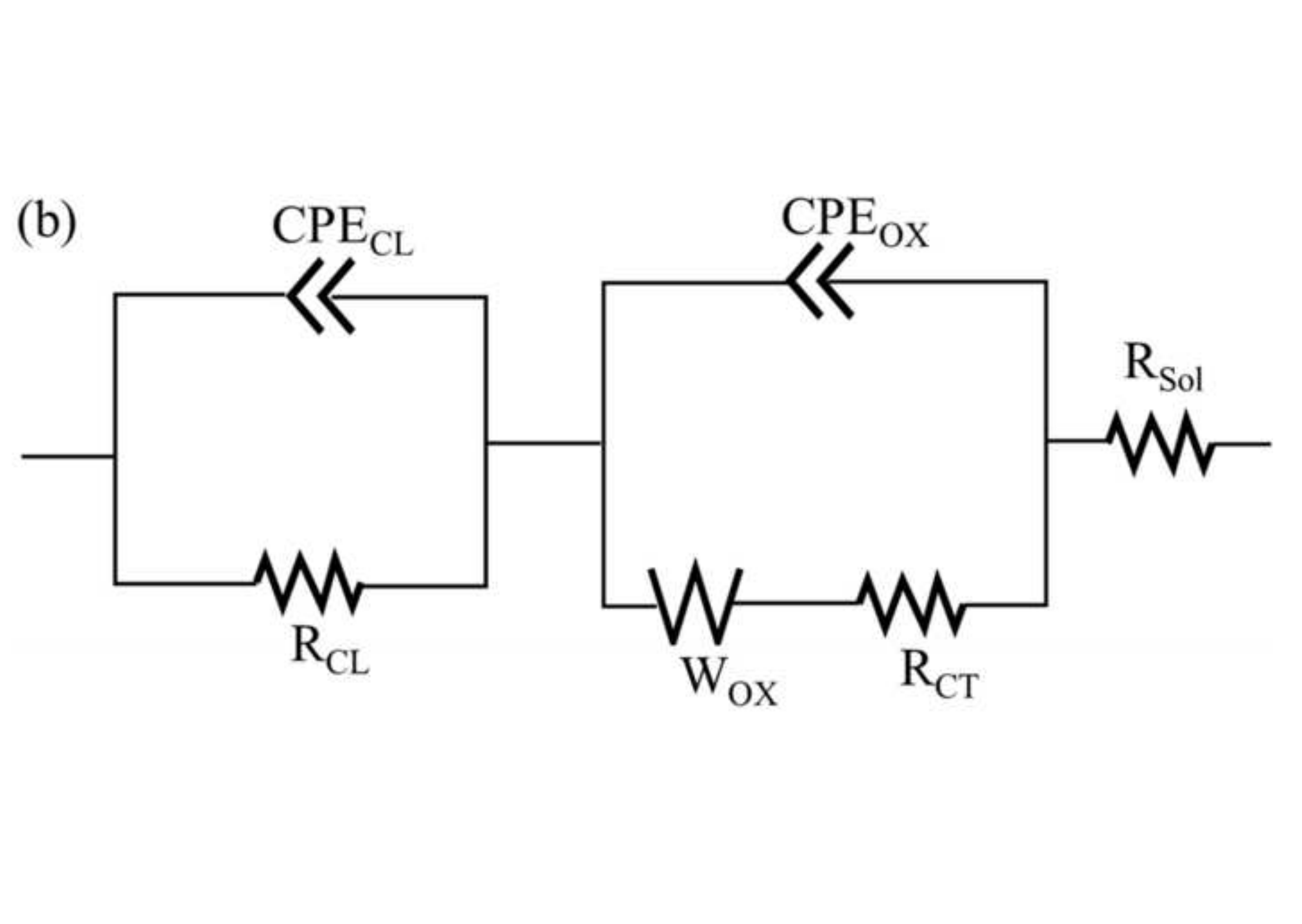

(b)

.
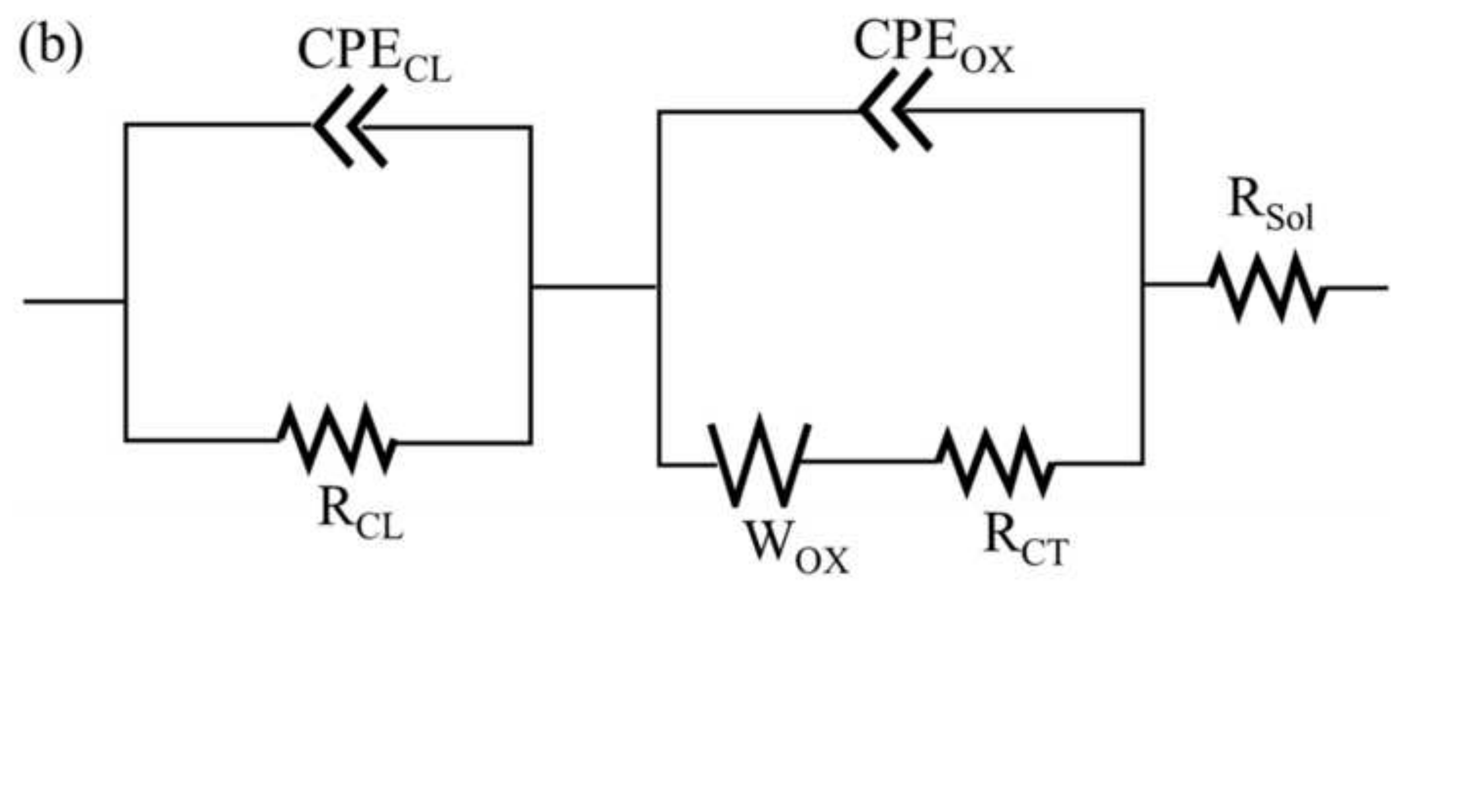

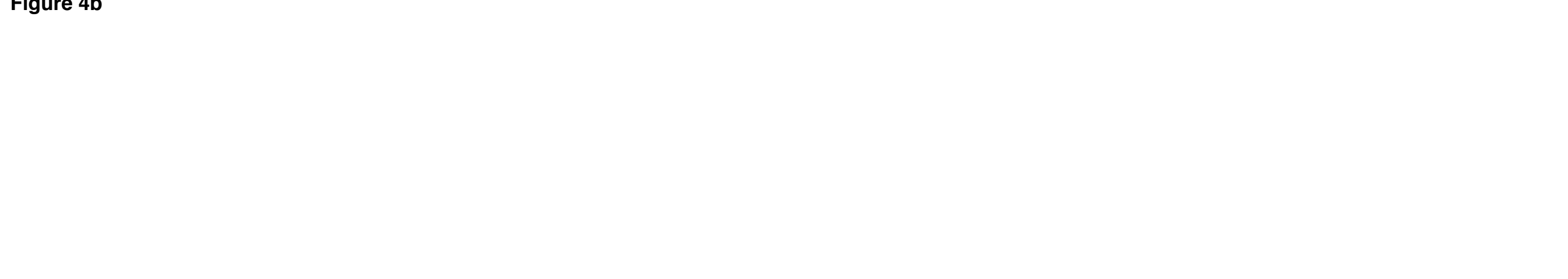

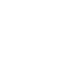


(a)

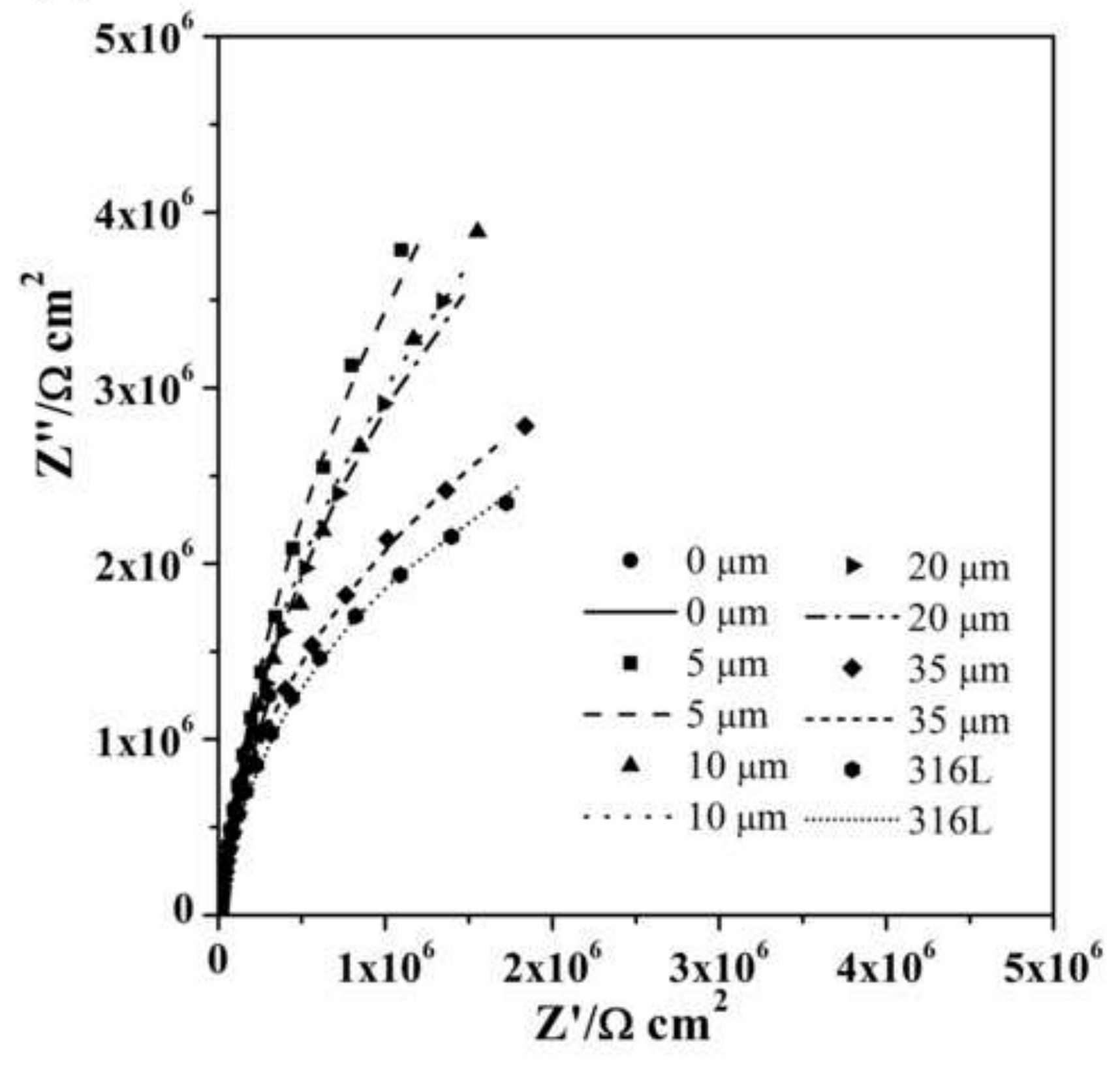

Figure $5 a$

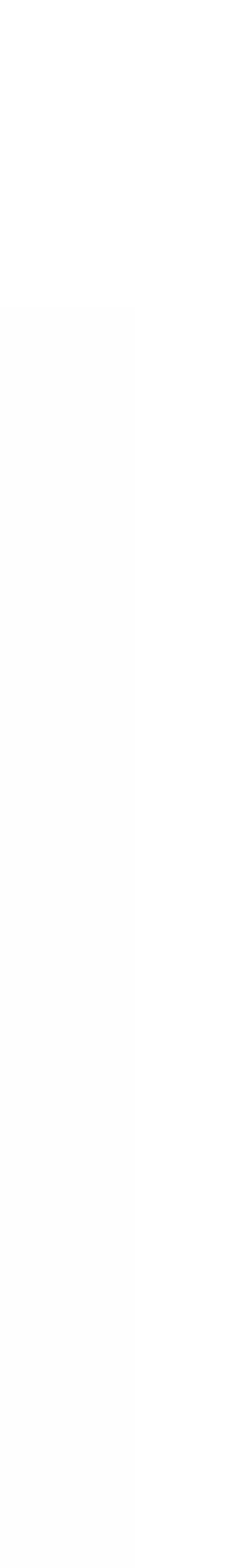

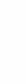


(b)

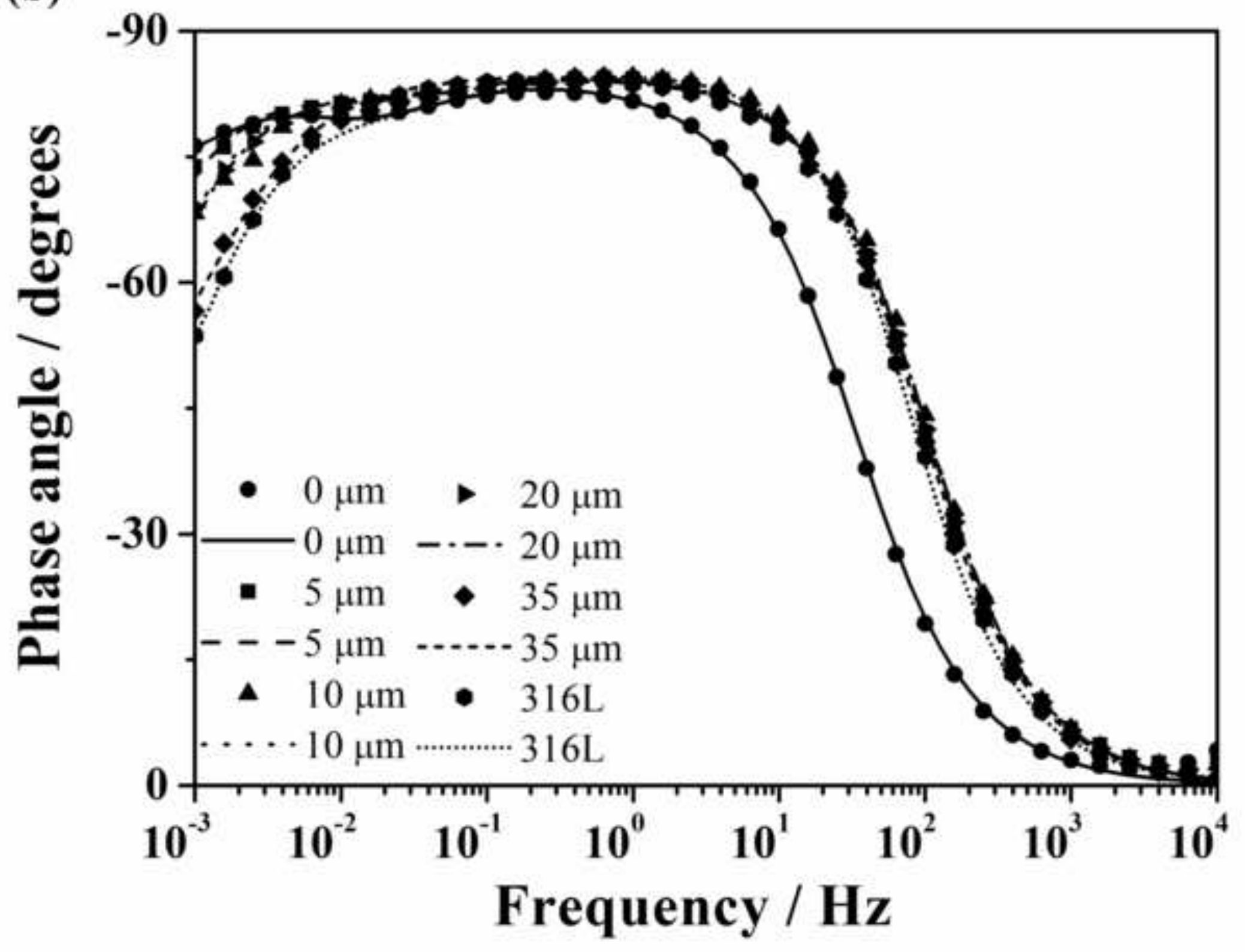




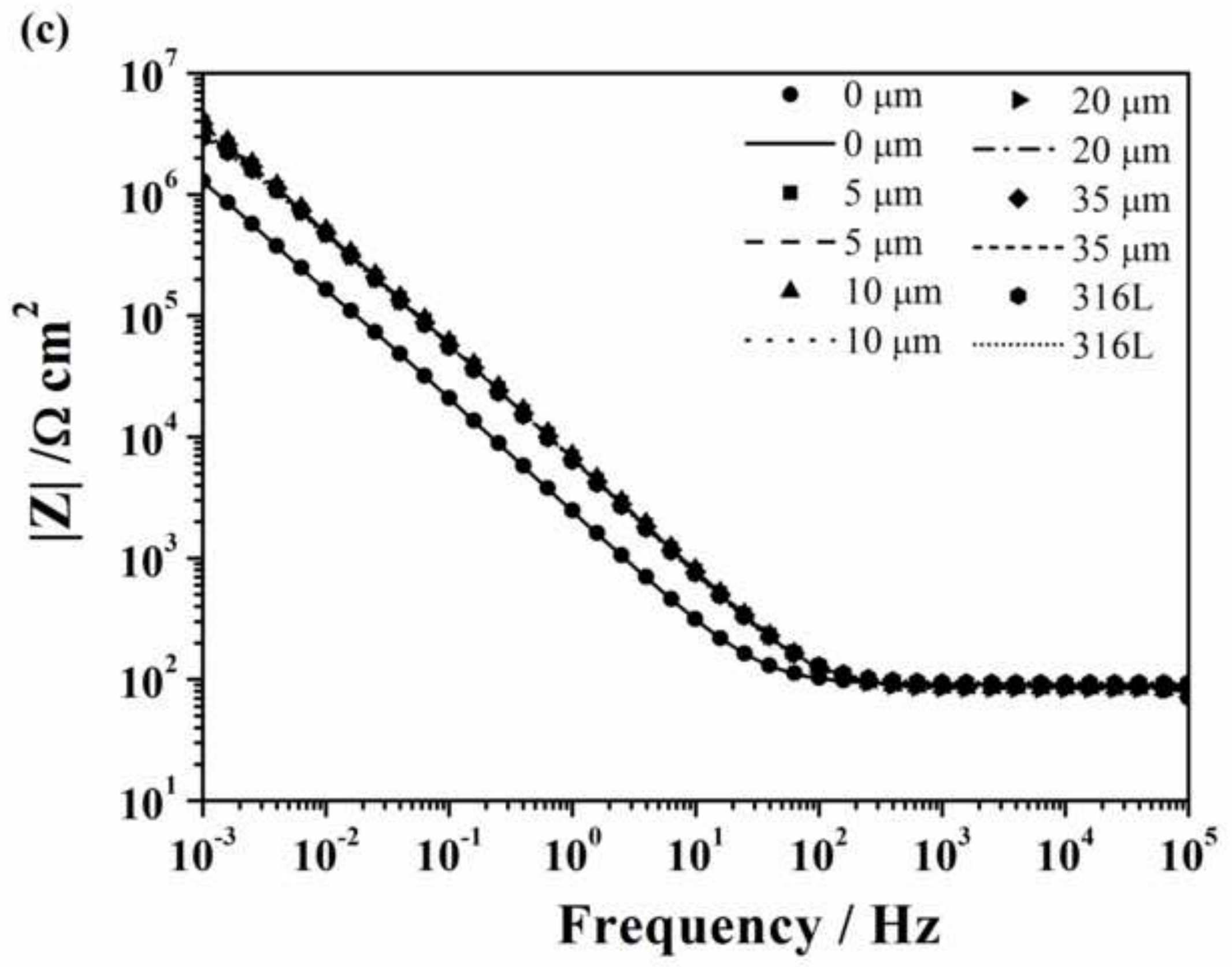


(a)

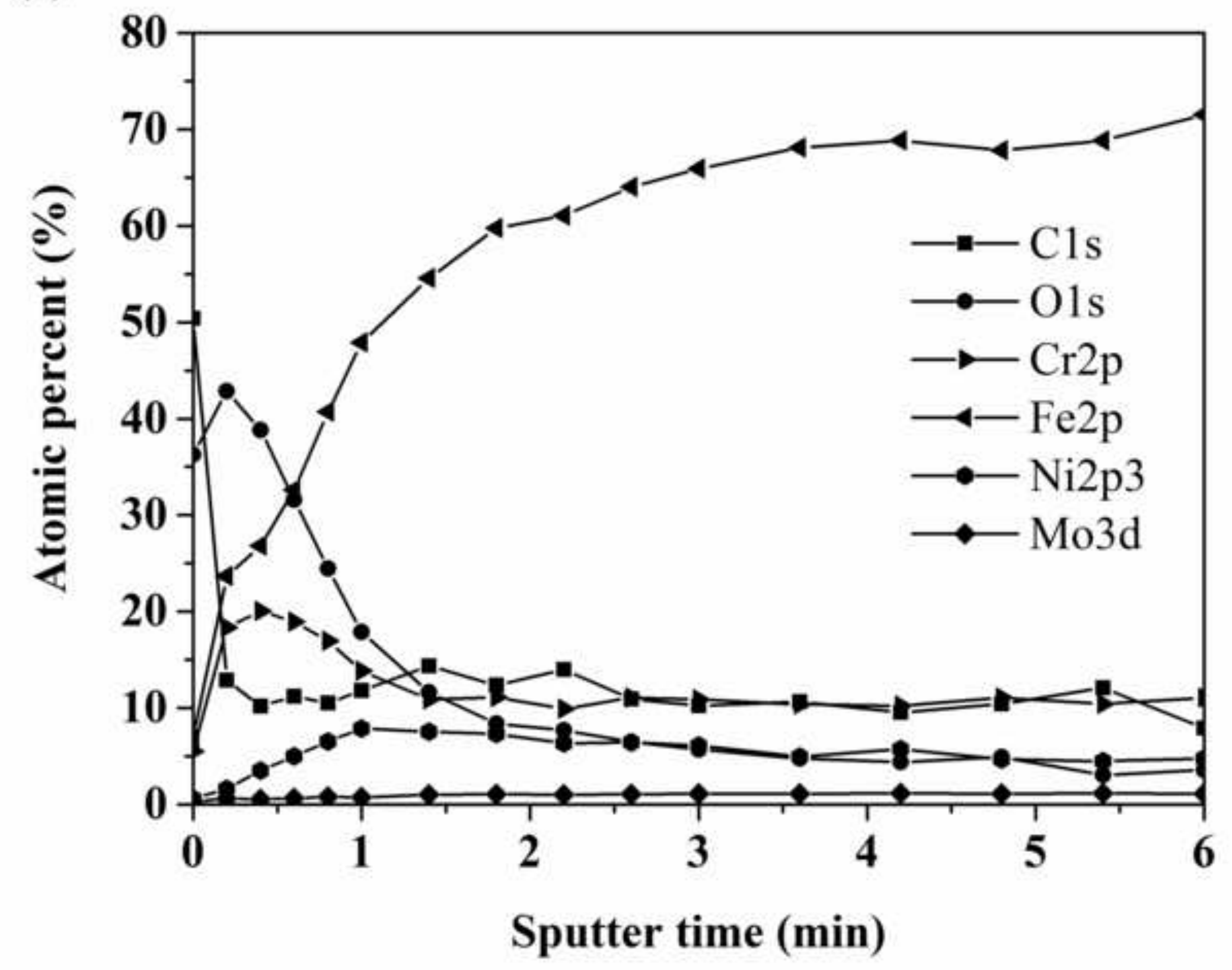


(b)

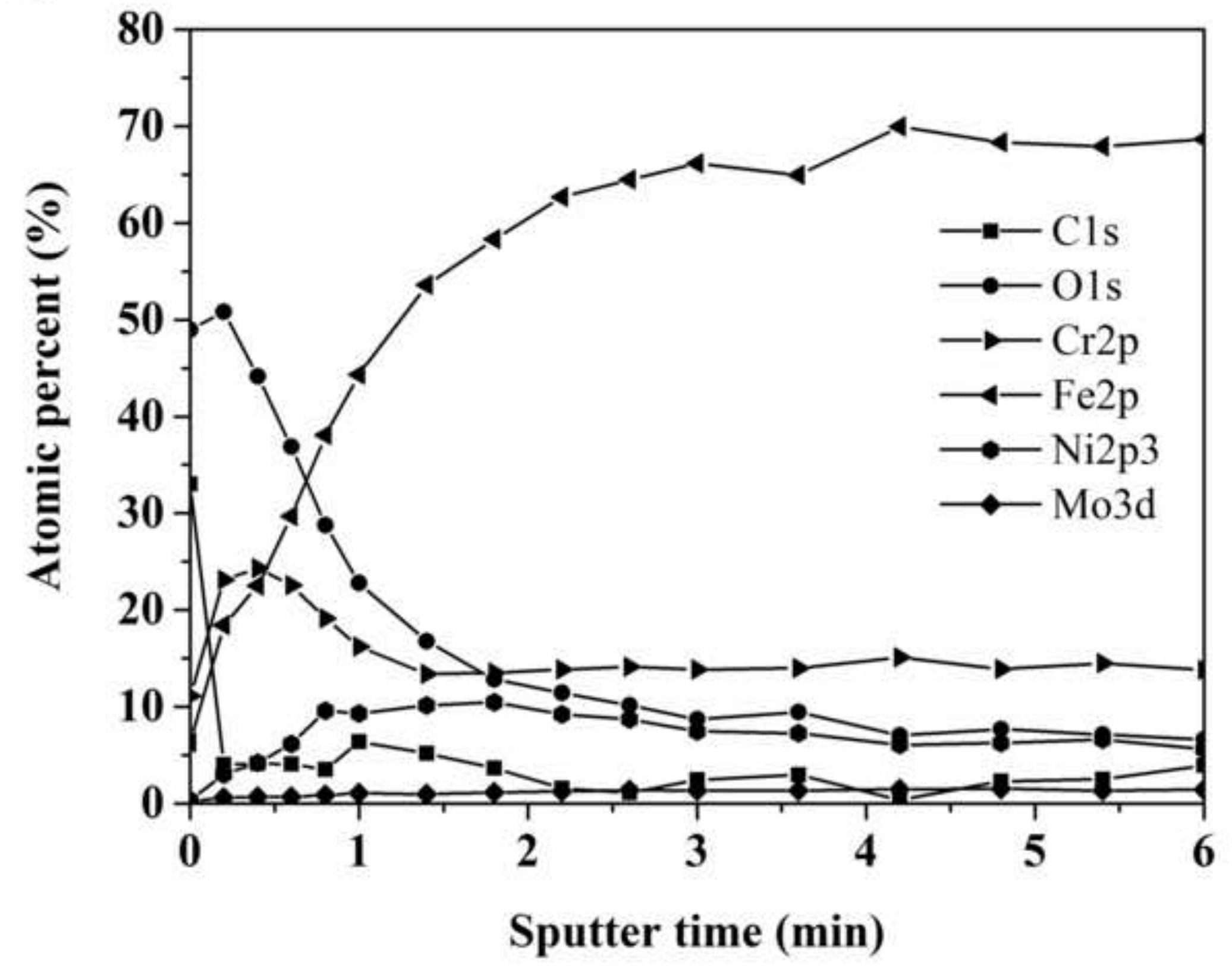


(a)

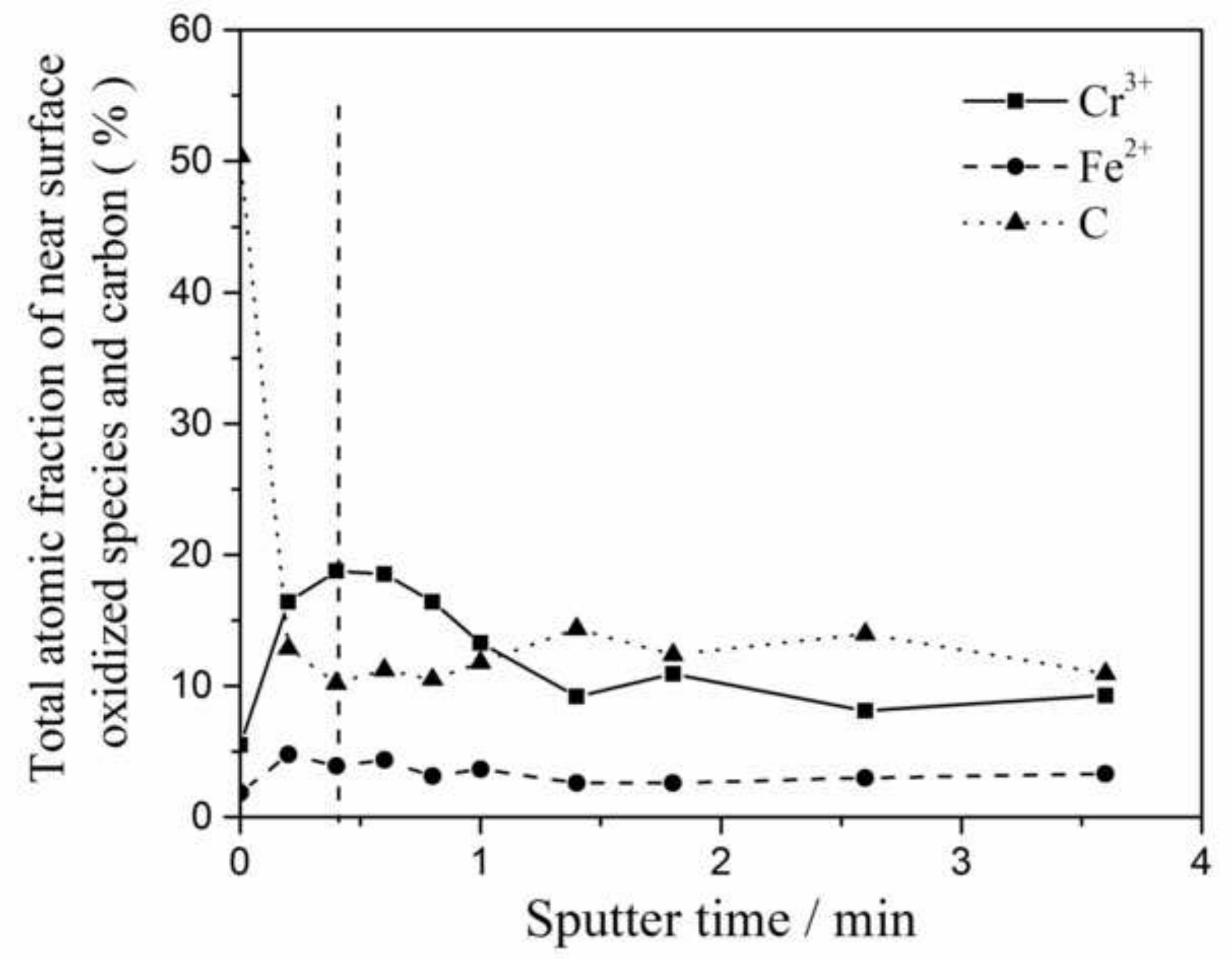




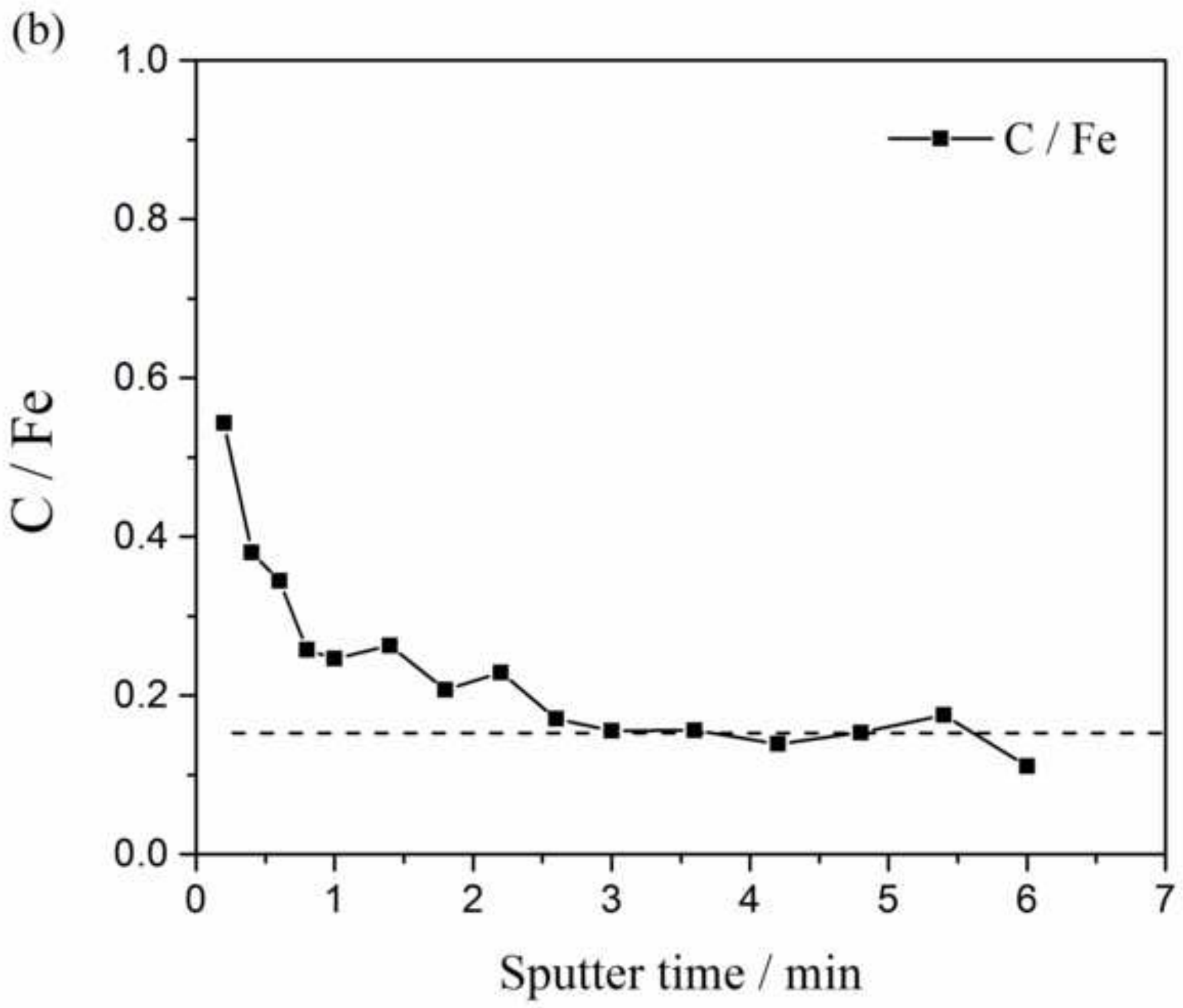


Figure $8 \mathrm{a} 1$
(a1)

Figure 8a1
$\begin{aligned} \text { (a1) }\end{aligned}$

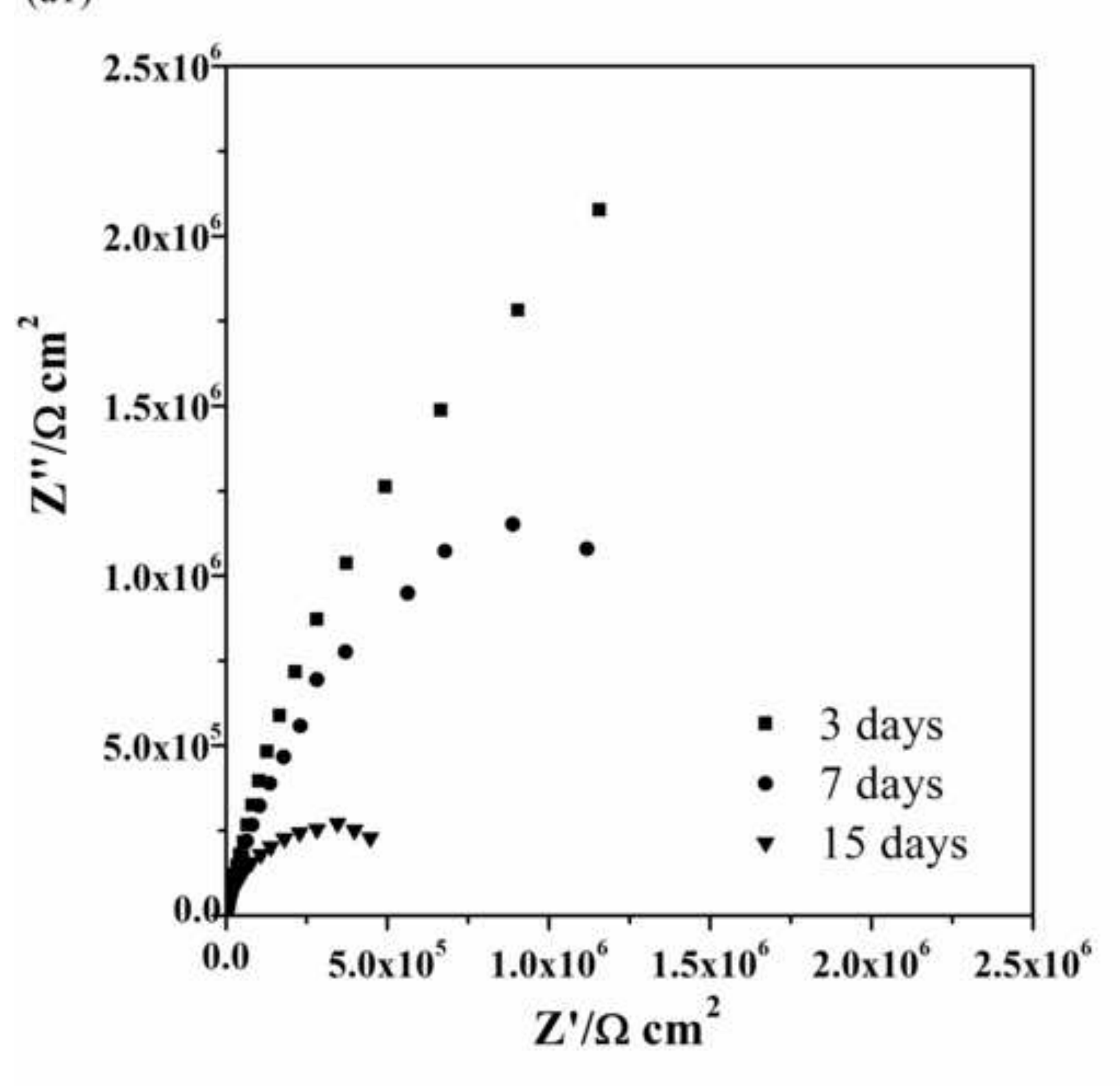

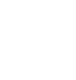

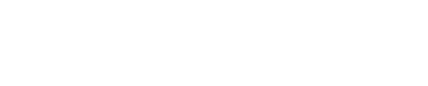

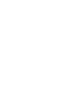

-

)

.
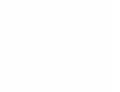
(a2)

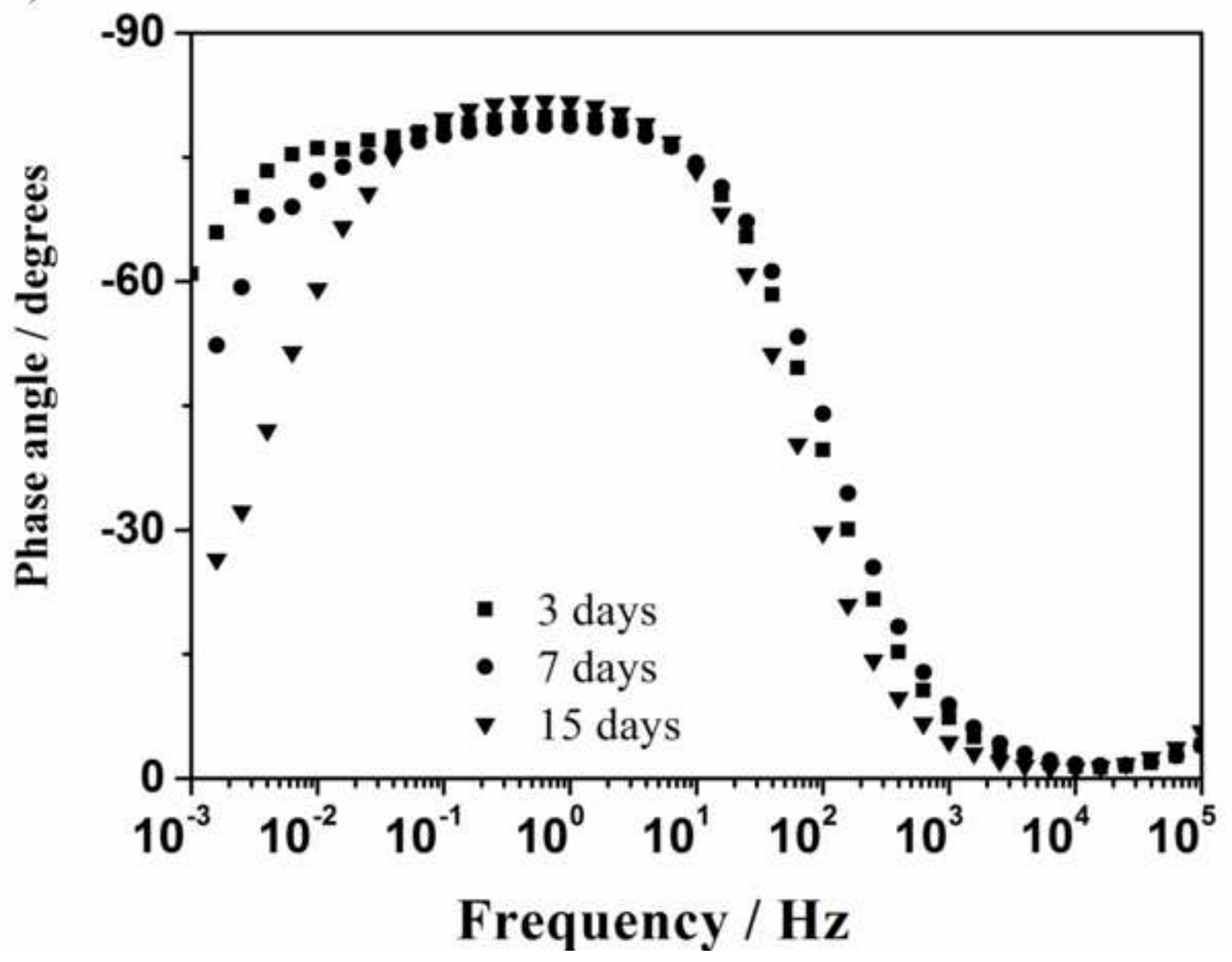


(a3)

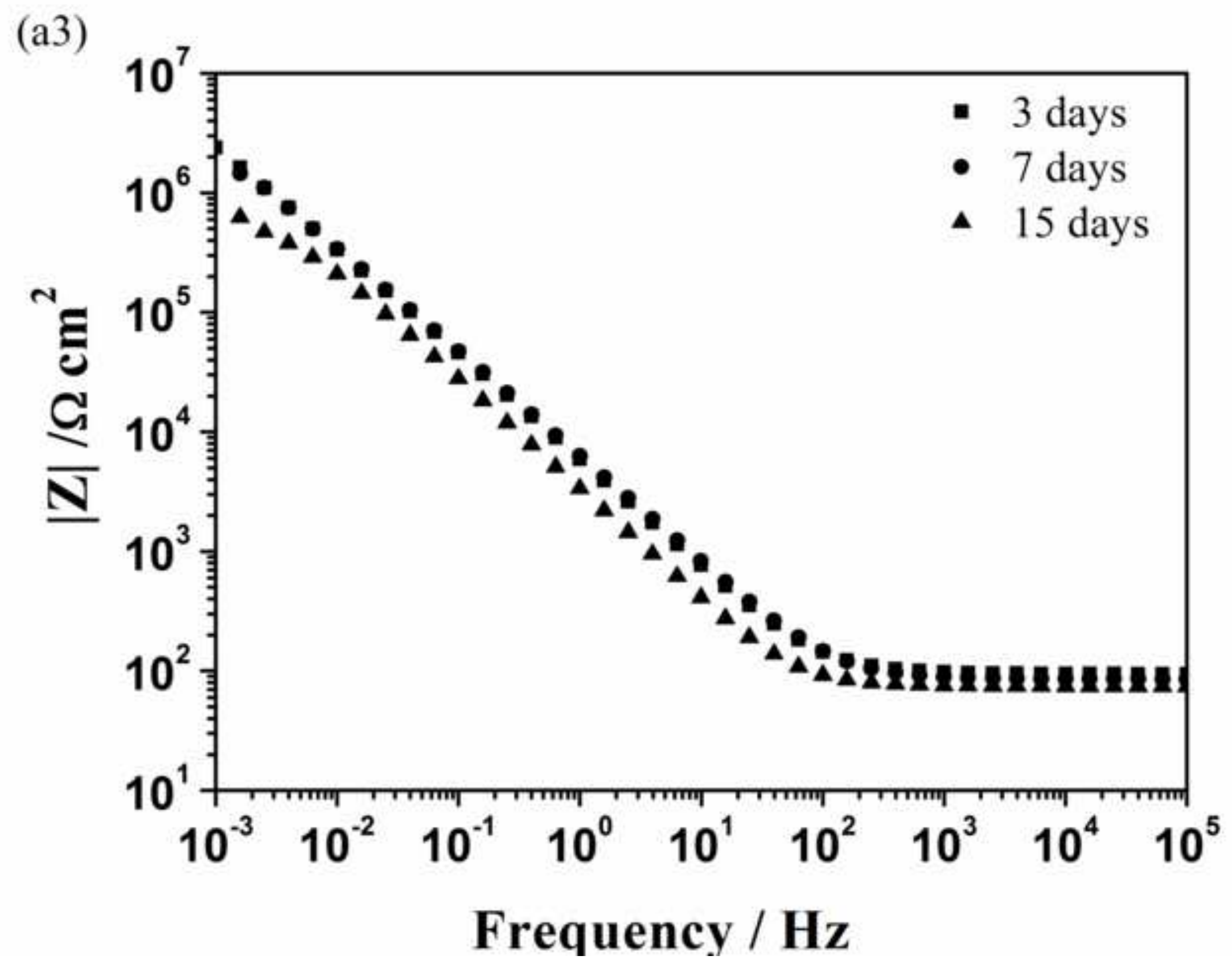


Figure 8b1

(b1)

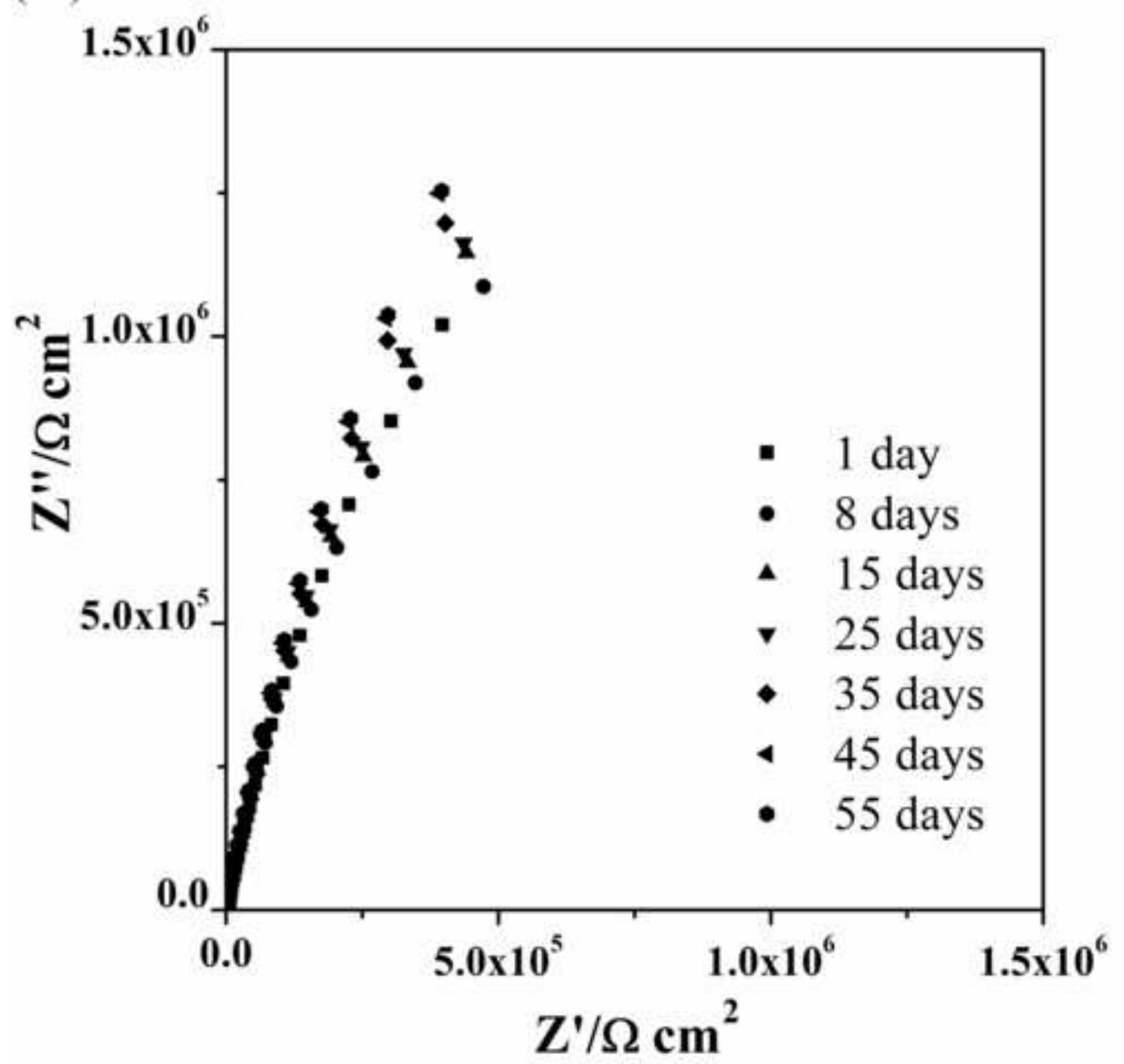


(b2)

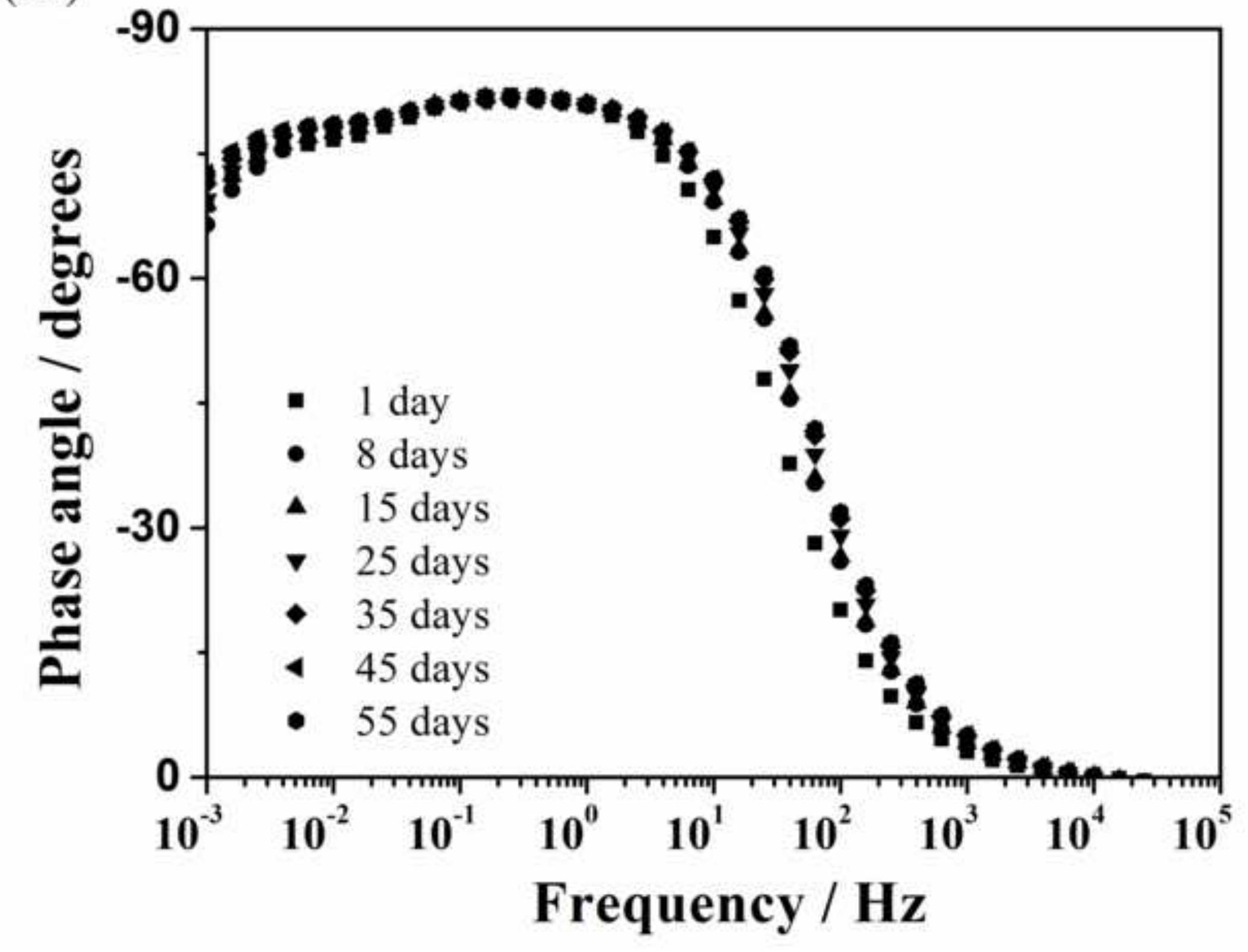




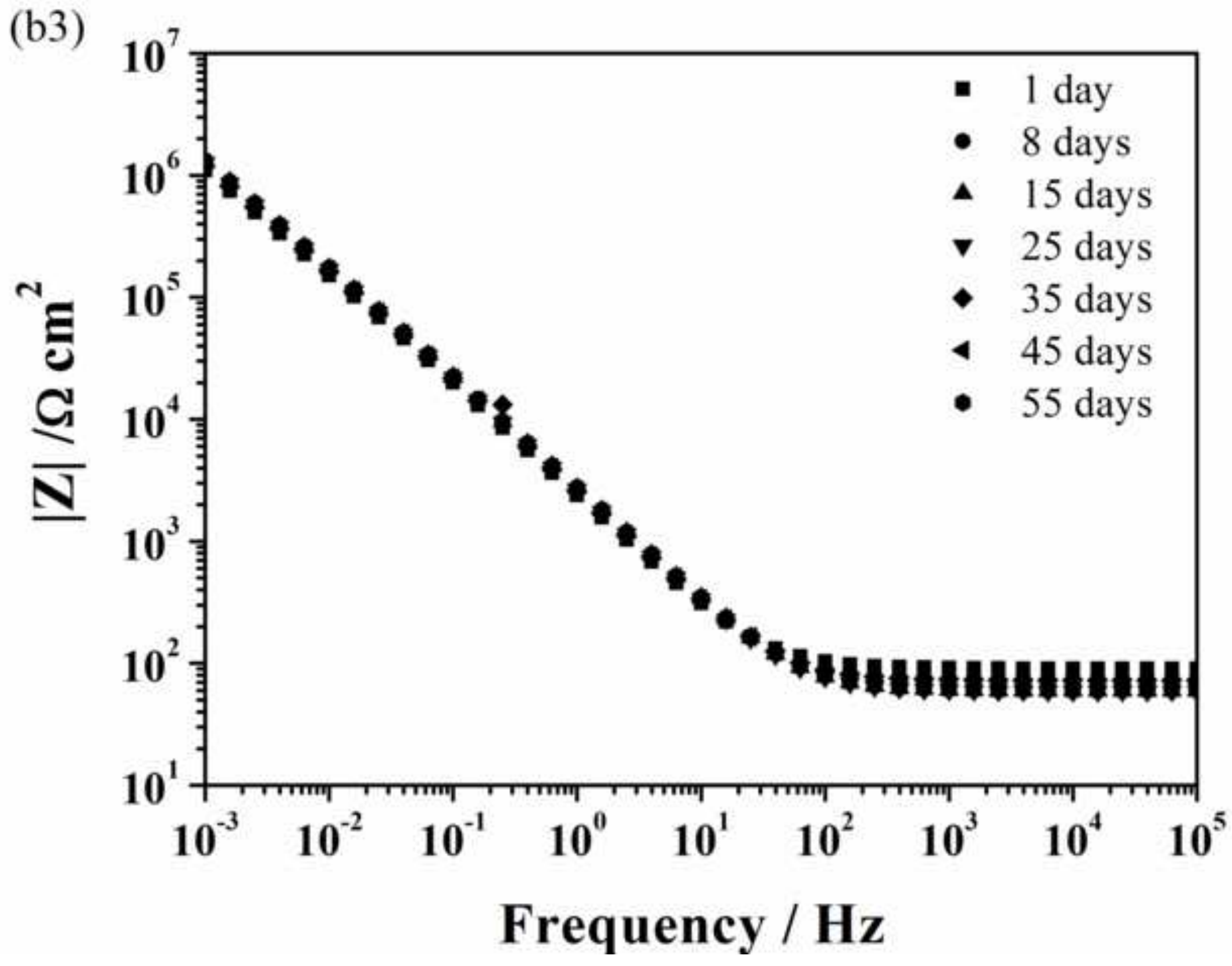




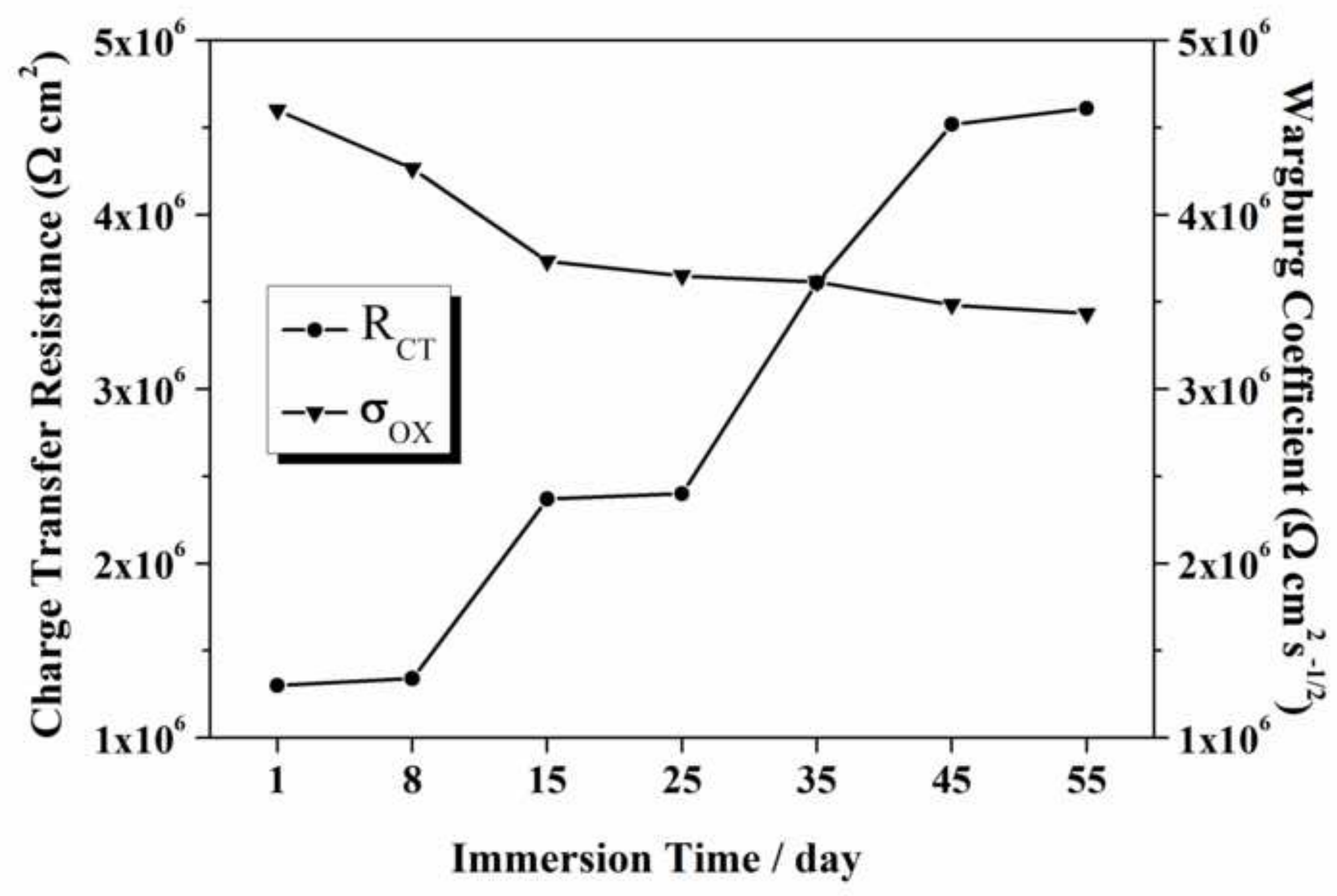


(a)

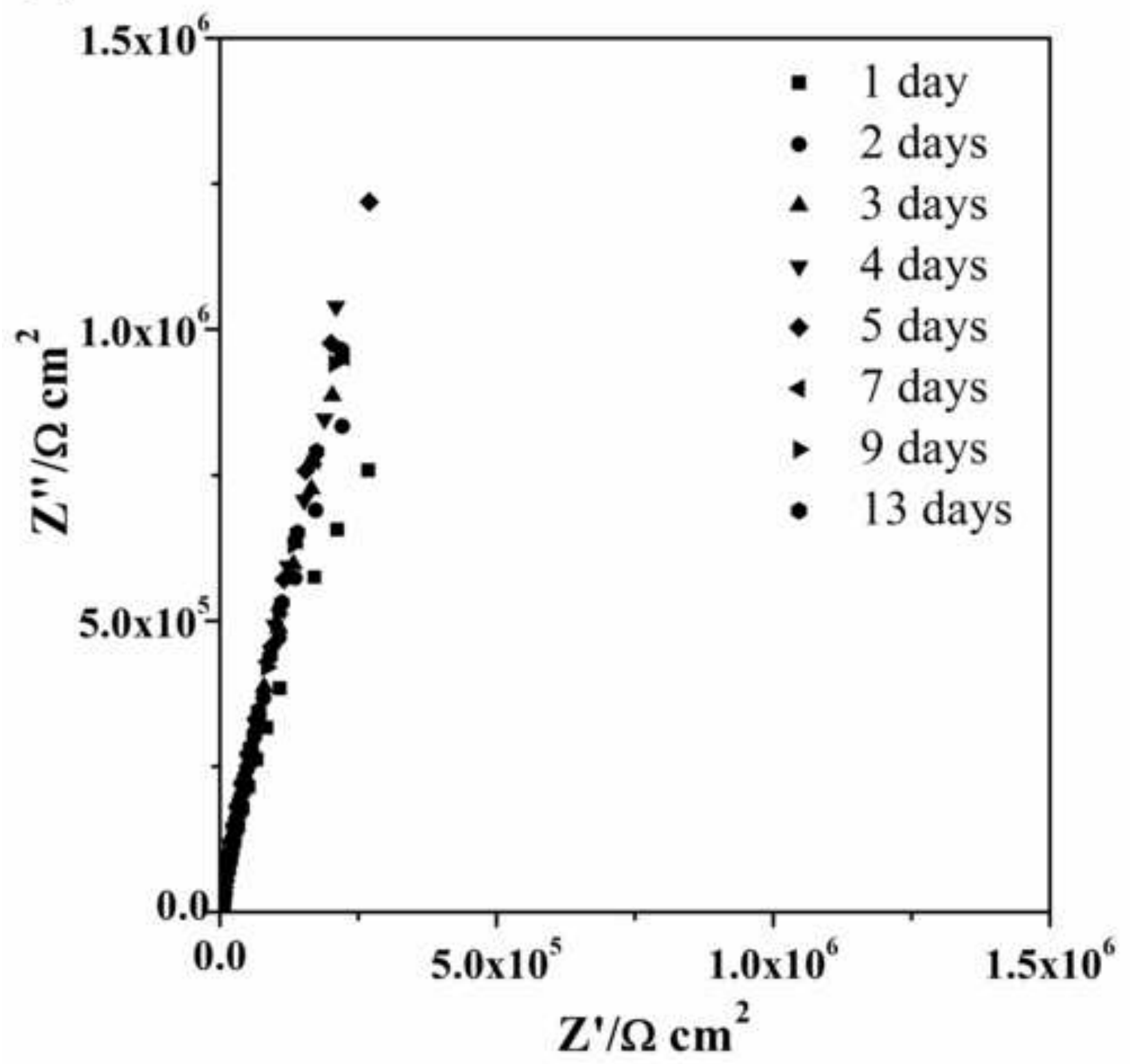

$Z^{\prime} / \Omega \mathrm{cm}^{2}$ 
(b)

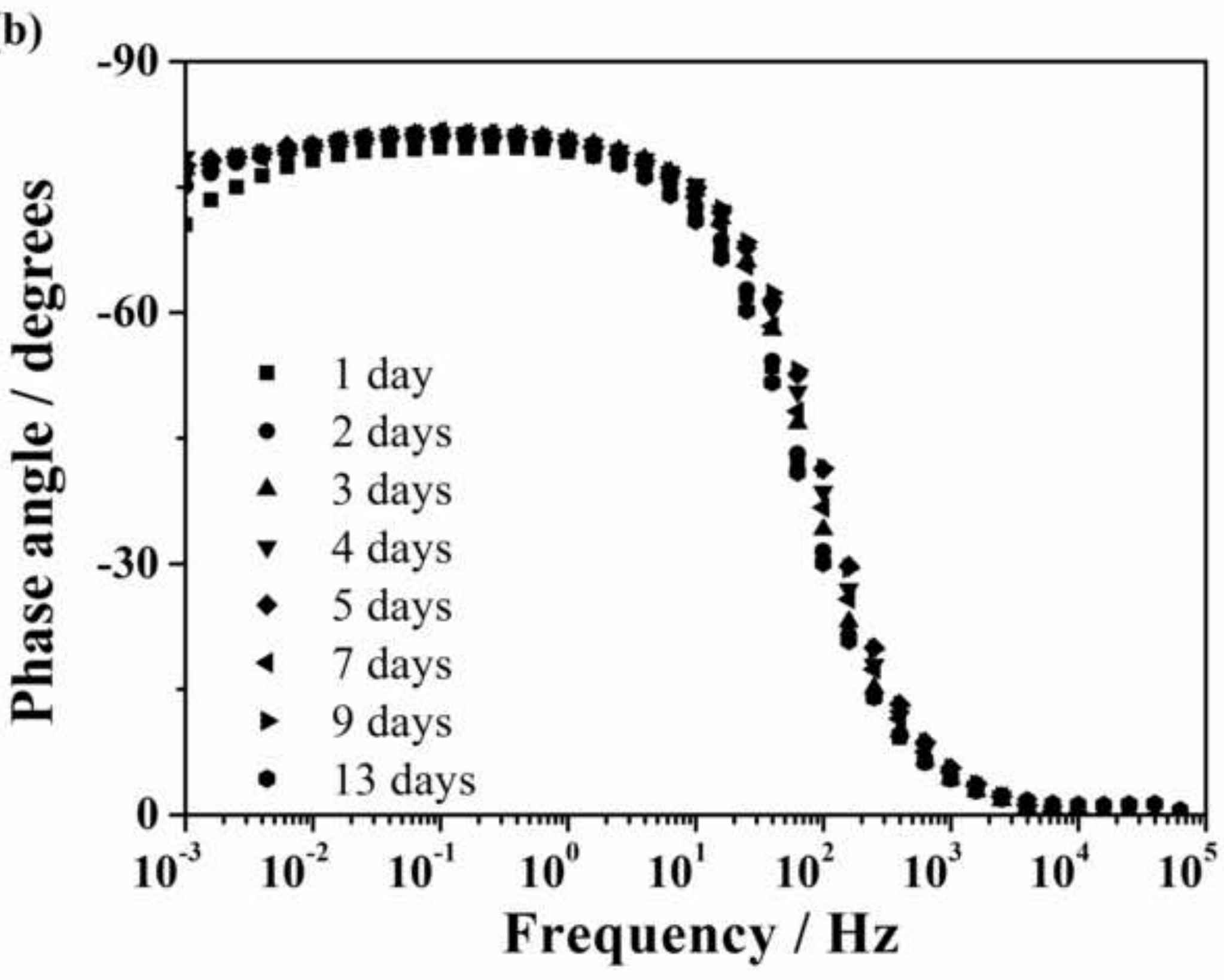




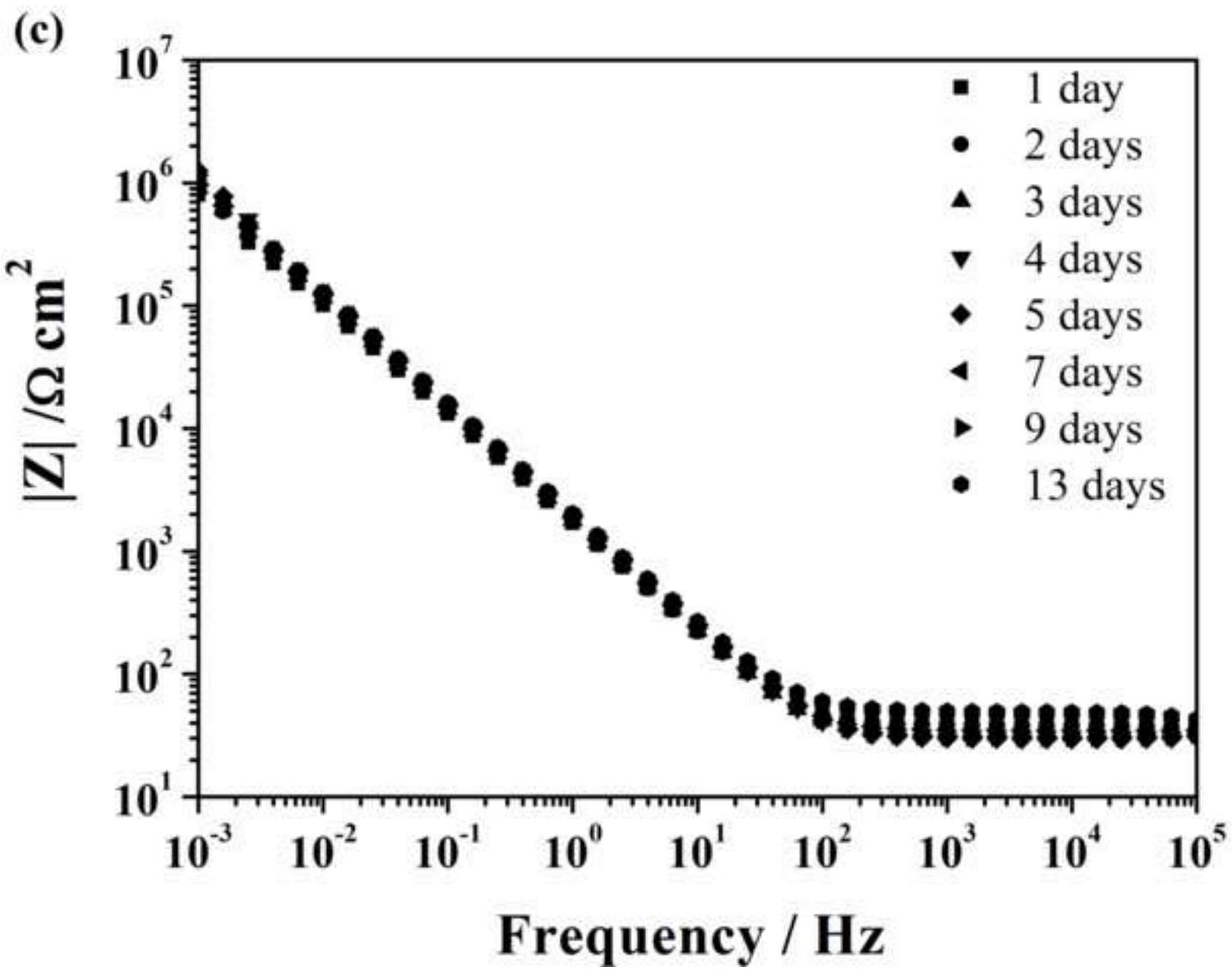




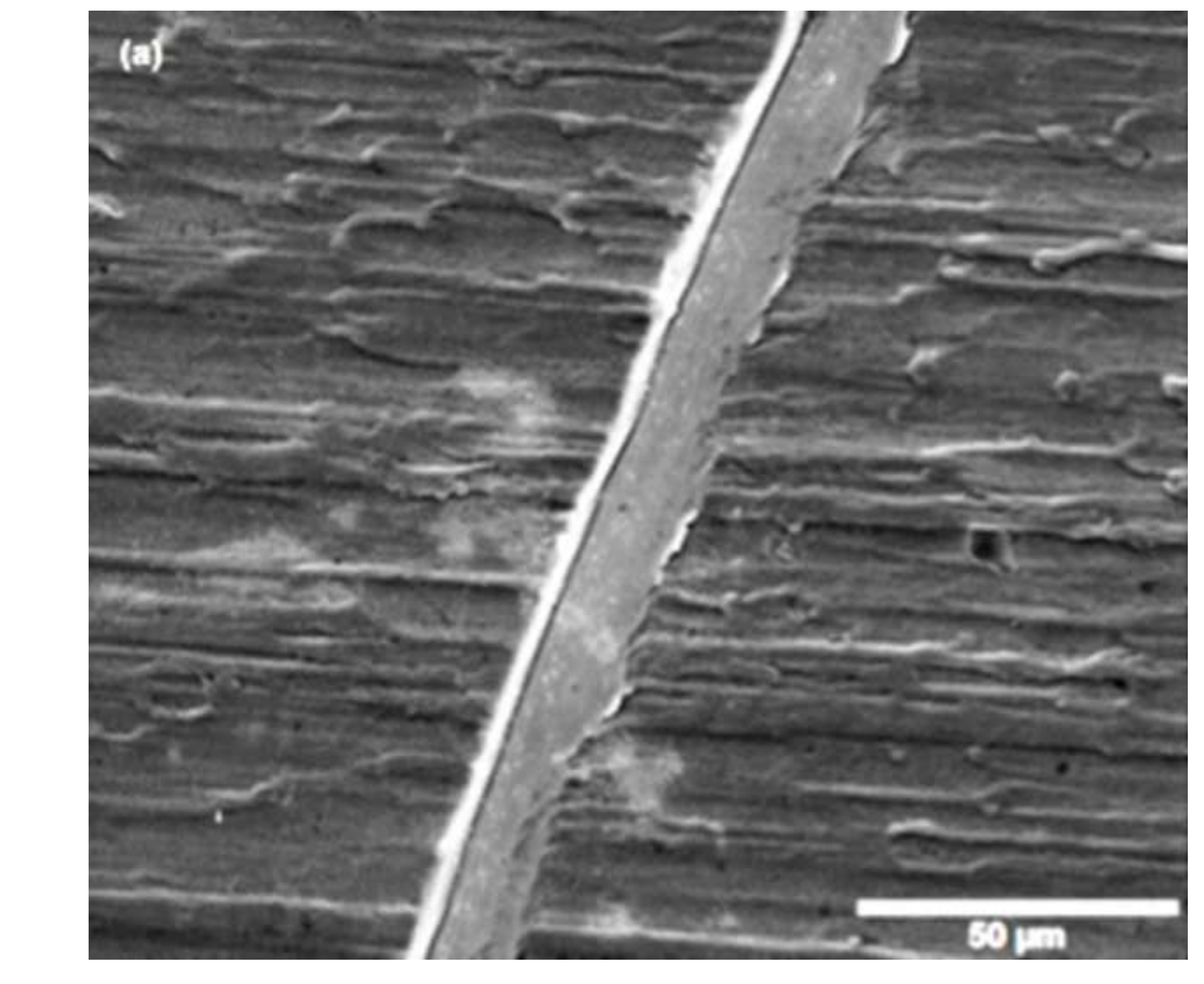




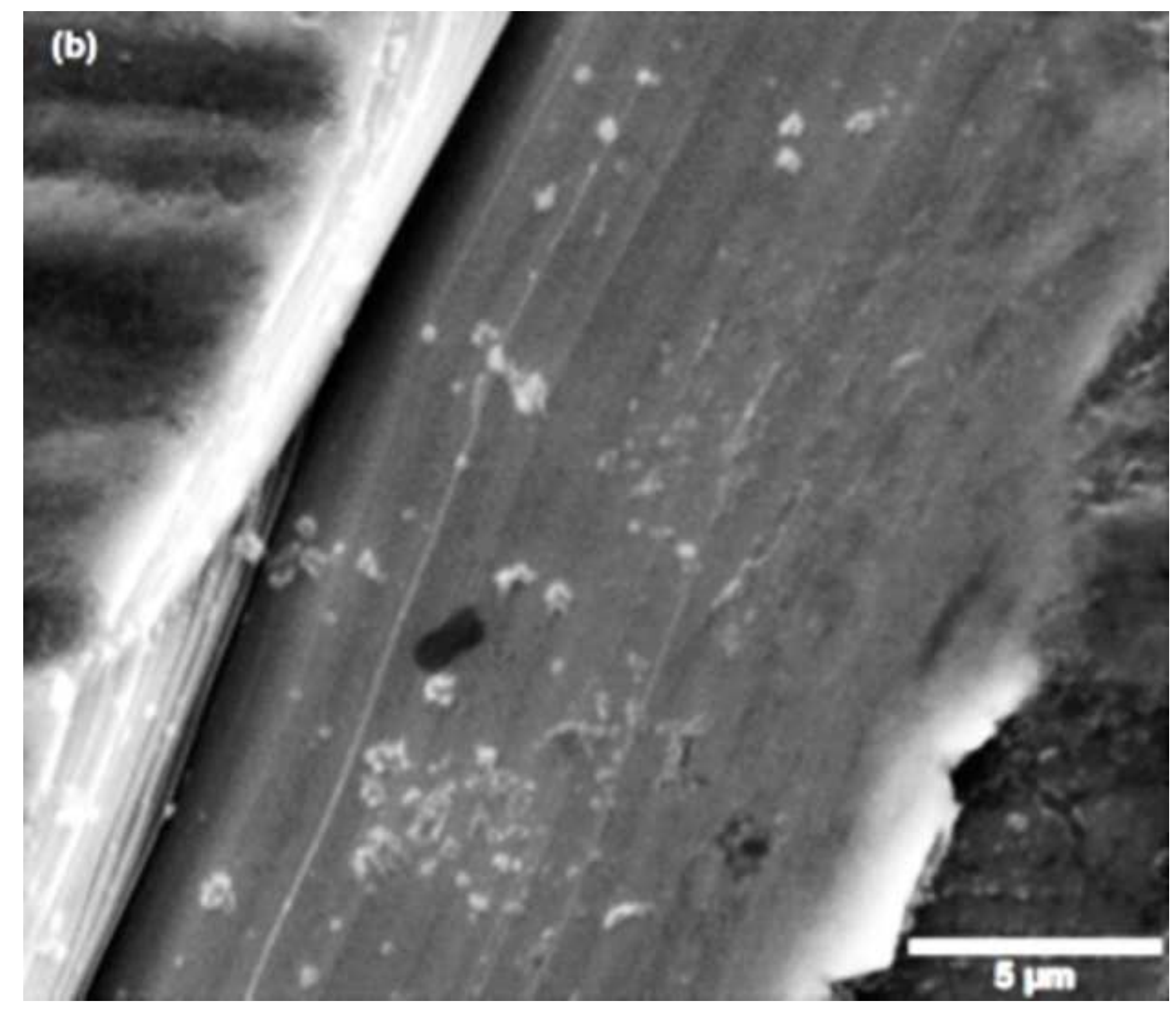

Figure 11
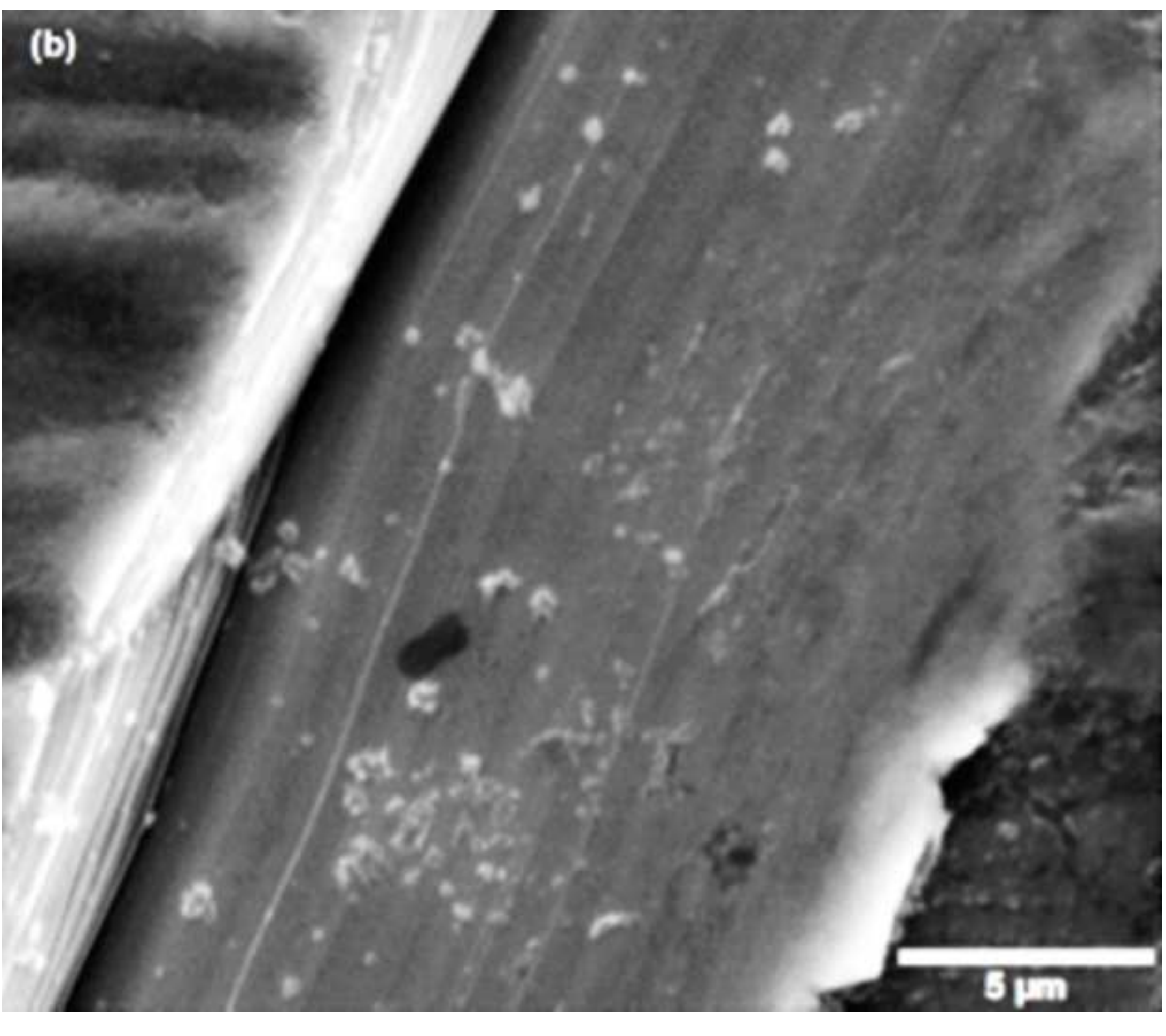


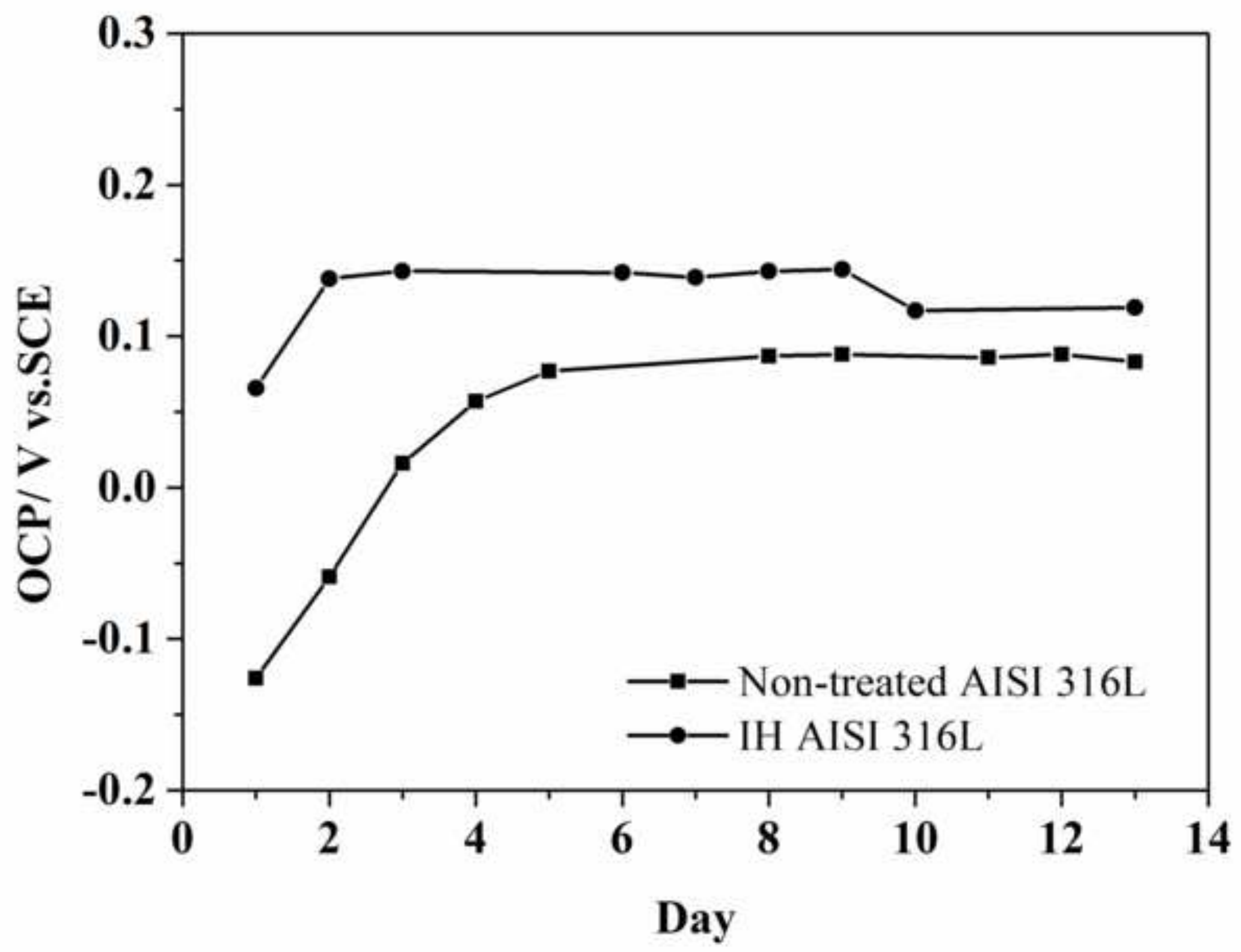

